Open Access

\title{
The effect of games and simulations on higher education: a systematic literature review
}

\author{
Dimitrios Vlachopoulos ${ }^{1 *}$ and Agoritsa Makri ${ }^{2}$
}

\author{
* Correspondence: \\ dimitrios.vlachopoulos@laureate.net \\ ${ }^{1}$ Laureate Online Education / \\ European University Cyprus, \\ Amsterdam, Netherlands \\ Full list of author information is \\ available at the end of the article
}

\begin{abstract}
The focus of higher education institutions is the preparation of future professionals. To achieve this aim, innovative teaching methods are often deployed, including games and simulations, which form the subject of this paper. As the field of digital games and simulations is ever maturing, this paper attempts to systematically review the literature relevant to games and simulation pedagogy in higher education. Two researchers collaborate to apply a qualitative method, coding and synthesizing the results using multiple criteria. The main objective is to study the impact of games and simulations with regard to achieving specific learning objectives. On balance, results indicate that games and/or simulations have a positive impact on learning goals. The researchers identify three learning outcomes when integrating games into the learning process: cognitive, behavioural, and affective. As a final step, the authors consolidate evidence for the benefit of academics and practitioners in higher education interested in the efficient use of games and simulations for pedagogical purposes. Such evidence also provides potential options and pathways for future research.

Keywords: Game-based learning, Digital games, Simulations, Pedagogical use, Higher education, Learning outcomes, Cognitive goals, Behavioural goals, Affective goals
\end{abstract}

\section{Introduction}

As rapidly evolving technological applications, games and simulations are already widely integrated in the traditional educational process. They are deployed extensively in the field of education, with an existing body of work examining the relation between games and education (Yang, Chen, \& Jeng, 2010; Chiang, Lin, Cheng, \& Liu, 2011). In recent years, digital or web-based games have increasingly supported learning. In the context of online education, this research area attracts a significant amount of interest from the scientific and educational community, for example tutors, students and game designers. With the growing expansion of technology, instructors and those who create educational policy are interested in introducing innovative technological tools, such as video games, virtual worlds, and Massive Multi-Player Online Games (MMPOGs) (Buckless, 2014; Gómez, 2014).

(C) The Author(s). 2017 Open Access This article is distributed under the terms of the Creative Commons Attribution 4.0 International License (http://creativecommons.org/licenses/by/4.0/), which permits unrestricted use, distribution, and reproduction in any medium, provided you give appropriate credit to the original author(s) and the source, provide a link to the Creative Commons license, and indicate if changes were made. 
Games and simulations show mixed effects across a number of sectors, such as student performance, engagement, and learning motivation. However, as these studies focus only on certain disciplines, there remains a gap in the literature concerning a clear framework of use across academic programmes. As a result, the issue of efficiently integrating games and simulations in the educational process is often up to the instructor's discretion. Accordingly, the aim of this paper is to develop a framework to allow educators across disciplines to better understand the advantages and draw backs of games and simulations specific to their pedagogical goals.

\section{Rationale of the study}

The researchers set out to examine the effectiveness of games and simulations in the learning experience, and immediately encounter the first challenge, which relates to a lack of clear empirical evidence on the issue (Farrington, 2011). The scientific field is too extensive and requires further investigation. Furthermore, there is currently no formal policy framework or guidelines recommended by governments or educational institutions on the adoption of games and simulations in education. This is the case for many countries in Europe, the US, and Australia, where it is the responsibility of the instructor or institution to incorporate games into the curriculum.

The main motivation for the current review lies in the fact that games are already, to a certain degree, integrated into educational systems to achieve a variety of learning outcomes (Connolly, 2012), yet a comprehensive policy is still lacking. In this paper, the first step was an attempt to conceptualize the terms "game" and "simulations". Although the two terms are neither wholly synonymous, or completely differentiated, in the main body of this review, the focus will be on lumping them together and perceiving them as points across a multidimensional continuum (Aldrich, 2009; Renken, 2016), since these educational technologies are consolidated under the umbrella of an interactive virtual environment in digital education.

A primary aim is to identify studies concentrating on the use of games and simulations for learning purposes, and to analyse the results by comparing them to prior studies' findings. Two research questions guide the review analysis: a) How can the best practices/methods for designing and incorporating games and simulations in student learning be identified? b) How can games/simulations enhance Higher Education?

The major difference between the current review and the previous reviews in the field is the conceptualization of the terms "games and simulations", which acts as an umbrella for further typologies. In other words, the researchers include more genres of games and simulations in their systematic review, compared to the other literature reviews. In addition, the researchers' intention is to focus on the impacts of games and simulations on learning outcomes. The researchers don't focus only on the cognitive outcomes, which is the most obvious and common topic among other researchers but, simultaneously, they analyze behavioural and affective effects as well. Furthermore, most of the previous reviews focus on the impacts of games and simulations on the learning process of certain subjects (e.g. Science, Business, Nursing, etc.), whereas this study expands research in a wide spectrum of academic disciplines and subjects. Overall, the current study offers a systematic review that 
opens new areas for further discussion, highlighting that collaborative learning, teamwork and students' engagement also play a significant role for a successful learning process.

\section{Conceptualising games and simulations}

\section{Games}

In recent years, the interest in examining game use in higher education has increased. This includes educational games (Çankaya \& Karamete, 2009), digital game-based learning (DGBL) (Yang, 2012), and applied games (van Roessel \& van Mastrigt-Ide, 2011). In addition, scholars, sometimes, include interactive exercises (Mueller, 2003), video games (Biddiss \& Irwin, 2010), or even expand to next generation video games (Bausch, 2008), in the category of games. With respect to web-based games, the technological platforms that implement digital game code include computers and consoles (Salen \& Zimmerman, 2004). They can run on a web browser on mobile phones and other mobile gaming devices (Willoughby, 2008) (e.g., tablets).

Despite the abundance of game types, there is a lack of clear, shared definitions and terminology among scholars and educators, which has led to "terminological ambiguity" (Klabbers, 2009). Nevertheless, the need for shared terminology remains when discussing the different forms of games and simulations in higher education. Although academics and game developers may use varying taxonomy to categorise games, the majority broadly agree on the following seven genres (Gros, 2007):

1. Action games: response-based video games.

2. Adventure games: the player solves problems to progress through levels within a virtual world.

3. Fighting games: these involve fighting with computer-controlled characters or those controlled by other players.

4. Role-playing games: players assume the roles of fictional characters.

5. Simulations: games modelled after natural or man-made systems or phenomena, in which players have to achieve pre-specified goals.

6. Sports games: these are based on different kinds of sports.

7. Strategy games: these recreate historical scenes or fictional scenarios, in which players must devise an appropriate strategy to achieve the goal.

In recent years, several well-designed empirical studies investigating the effects of serious games on learning outcomes have been published. Sawyer refers to serious games as those games produced by the video game industry that have a substantial connection to the acquisition of knowledge (Sawyer, 2002). Zyda (2005) expands Sawyer's definition, adding that serious games are games whose primary purpose is not entertainment, enjoyment or fun. Serious games, educational gaming, as well as virtual worlds developed for educational purposes reveal the potential of these technologies to engage and motivate beyond leisure activities (Anderson et al., 2009). At the same time, there is extensive literature exploring the potential learning benefits offered by game-based learning (GBL), which can be defined as the use of game-based technology to deliver, support, and enhance teaching, learning, assessment, and evaluation (Connolly, 2007). 


\section{Simulations}

Simulations create a scenario-based environment, where students interact to apply previous knowledge and practical skills to real-world problems, also allowing teachers to reach their own goals, as well (Andreu-Andrés \& García-Casas, 2011; García-Carbonell \& Watts, 2012; Angelini, 2015). During scenario-based training, the player acquires important skills, such as interpersonal communication, teamwork, leadership, decision-making, task prioritising and stress management (Flanagan, 2004). The practical scenario may be carried out individually or within a team (Robertson et al., 2009), leading to collaboration and knowledge sharing.

With the explosion of Web 2.0 technology, increased opportunities to engage with technological applications in a collaborative and participatory way have emerged, promoting information access, shared ideas, knowledge exchange, and content production (McLoughlin \& Lee, 2008). Digital simulations, which engage students in the interactive, authentic, and self-driven acquisition of knowledge, are being adopted in higher education. Connolly and Stansfield (2006) define game-based e-learning as a digital approach which delivers, supports, and enhances teaching, learning, assessment, and evaluation. Game-based e-learning is differentiated from GBL, which tends to cover both computer and non-computer games.

Delivery platforms are an essential aspect for game designers when creating and distributing games and simulations (e.g. computer, video, online, mobile, 3D, etc.). Designers must pay attention to characteristics such as the technical challenges, modules and techniques associated with the game design, the players involved in gaming, and the teaching modes (e.g. single, multi-player, collaborative, synchronous, etc.). This study examines the diverse curricular areas and learning objectives each game intends to access. The above-mentioned game classification is presented below (Fig. 1).

The main difference between games and simulations is the following: games are tools which are artificial and pedagogical; they include conflict, rules, and predetermined goals, whereas simulations are dynamic tools, representing reality, claiming fidelity, accuracy, and validity (Sauve, 2007).

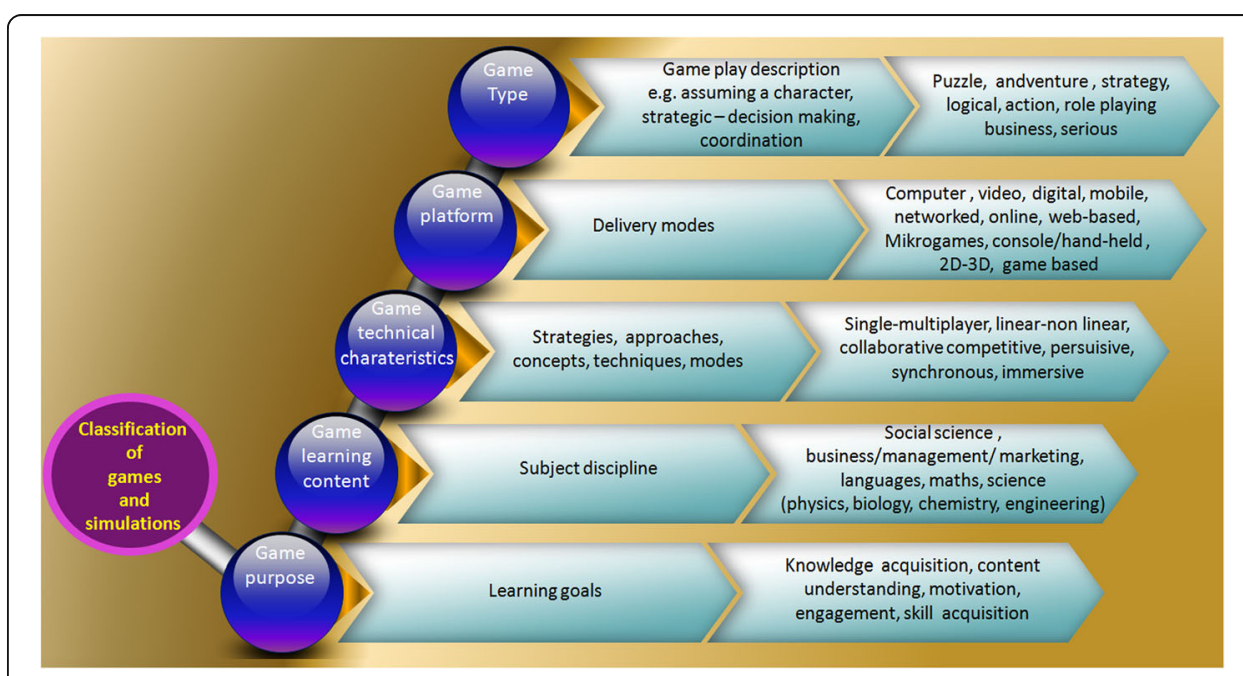

Fig. 1 Classification of games and simulations 


\section{Previously conducted reviews/meta-analyses on games and simulations in higher education}

To establish a context, the researchers, initially, examined the relevant literature on the effectiveness of all types of games and simulations in learning outcomes. Many papers are analysed and summarised as follows, providing useful guidance for this study.

Through their systematic review, Tsekleves et al. (2014) provide insight into the barriers and benefits of using serious games in education. (Regarding benefits, the authors catalogue: achievement and rewards, interactivity and feedback, motivation and competition, playfulness and problem-based learning, collaborative learning, progression and repetition, as well as realism and immersion. Finally, they propose some guidelines to help stakeholders better implement serious games in education. Similarly, Bellotti, (2013) suggest useful guidelines for the performance assessment of serious games. Following user performance assessments, they offer an overview on the effectiveness of serious games in relation to learning outcomes. Results reveal the effectiveness of serious games in motivating and achieving learning goals, the importance of providing appropriate user feedback, while emphasizing that new types of games are best deployed through proper instructor guidance. Moreover, they stress aspects they consider important, such as performance assessment with a view to fostering adaptivity, as well as personalisation, and meeting needs on an individual basis (e.g. learning styles, information provision rates, feedback, etc.).

The instructor's role is also outlined by Lameras et al. (2016) who provide conceptual and empirical evidence on the manner in which learning attributes and game mechanics should be designed and incorporated by faculty, specifically with a view to fully integrate these into lesson plans and the learning process as a whole. Games allow practitioners to quickly come to grips with the way in which learning activities, outcomes, feedback and roles may vary, as well as to enhance the in-game learning experience. Similarly, the systematic review of 64 articles by de Smale, (2015) concludes that there is a positive or neutral relationship between the use of simulations and games and learning achievement. The researchers arrive at three recurring conditions for the successful use of simulations and games: the specificity of the game, its integration in the course, and the role of a guiding instructor, which are all conditions in line with Bellotti et al. (2013)'s results.

Young et al. (2012) choose 39 articles that meet the inclusion criteria related to video games and academic achievement, concentrating on the use of traditional games versus video games for educational purposes. The studies are categorised by subject, namely History, Mathematics, Physical Education, Science, and Languages. Results indicate that there exists limited evidence of the benefits of including education games in the traditional classroom environments, a finding which is contrary to the aforementioned studies. Smetana and Bell (2012) examine computer simulations to support instruction and learning in Science. In their comparative study between computer games and traditional games, they conclude that computer games can be as effective, if not more so, than traditional games in promoting knowledge, developing procedural skills and facilitating conceptual change. To integrate them properly as supplementary elements (Rajan, 2013), games require the adoption of high-quality support structures, student participation, as well the promotion of cognitive and metacognitive skills. This finding contradicts the study carried out by Girard, (2013). This study treats video games as 
serious games but considers their effectiveness as a controversial issue, finding that only few games result in improved learning, while others have no positive effect on knowledge and skills acquisition, when compared to more traditional methods of teaching.

In contrast, in their meta-analysis, Clark et al. (2015) systematically review articles to study the detailed effects of digital games on learning outcomes, concluding that games are important in supporting productive learning and highlighting the significant role of gaming design beyond its medium. Prior to this review, but running along the same lines, Backlund and Hendrix (2013), in their meta-analysis reported positive outcomes in learning when using serious games in the educational process. Wouters, (2013) performing meta-analytic techniques, used comparisons as well, to investigate whether serious games are more effective and more motivating than conventional instructional methods. They found higher effectiveness in terms of learning and retention, but less motivation compared to traditional instructional methods. Indeed, serious games tend to be more effective if regarded as a supplement to other instructional methods, and involve students in groups and multiple training sessions.

These findings are compatible with those in the survey conducted by Rutten, (2012), which focuses on implementing games as laboratory activities, concluding that simulations have gained a prominent position in classrooms by enhancing the teacher's repertoire, either as a supplement to traditional teaching methods or as a partial replacement of the curriculum. Nevertheless, they stress that the acquisition of laboratory skills cannot be wholly conducted via simulations. However, in areas where simulations have been widely accepted as a training tool, simulations can play a significant role in making lab activities more effective when offered as pre-lab training. Fu, (2016), through a systematic literature review, identify the multi-dimensional positive impact of serious games in business education, with the most frequent outcomes being knowledge acquisition and content understanding. The study also confirms that GBL and serious games can influence player engagement, perpetual and cognitive skills and social or soft skills. The affective and motivational outcomes are examined in entertainment games, games for learning and serious games, which reflects the trend of using gaming elements as both a medium of entertainment as well as a mode of learning. Ritzhaupt, (2014) produce meta-analysis based on 73 articles, demonstrating that achievement measures (e.g., standardised test scores) are the most commonly investigated, while the second most frequent is affective measures (e.g., usability or attitudes towards technology) followed by behavioural measures (e.g., task behaviour).

Merchant, (2014), via a meta-analysis, compare the effectiveness of games, simulations and virtual worlds in improving learning outcomes. Findings indicate that playing games individually enhance student performance more than playing collaboratively. Nonetheless, the researchers claim that there is no statistically significant difference between the effects of individual and cooperative instructional modules regarding simulations. Student learning outcomes deteriorate after repeated measures, since after spending a certain amount of time playing games, the learning outcome gains start to diminish. On the contrary, Shin, (2015), through meta-analysis, aim to identify the effects of patient simulation in nursing education. They find significant post-intervention improvements in various domains for participants who receive simulation education compared to the control groups, thus leading to the conclusion that simulations are more effective than 
traditional learning methods, enhancing the player's psychomotor, affective, and cognitive skills. In their work, simulations provide students with authentic clinical situations, allowing them to practice and experience in realistic and safe environments.

Connolly et al. (2012) develop a multi-dimensional approach to categorising games and offer a review of 129 papers on computer games and serious games, explicitly targeting cognitive, behavioural, affective and motivational impacts, as well as engagement. The most frequent outcomes are knowledge acquisition and content understanding, as well as affective and motivational outcomes. Gegenfurtner, (2014) in their meta-analysis of the cognitive domain, examine how design elements in simulation-based settings affect self-efficacy and transfer of learning. They conclude that gathering feedback post-training, as opposed to during the process, results in higher estimates of self-efficacy and transfer of learning.

Researchers also look at games and simulations from a theoretical perspective. $\mathrm{Li}$ and Tsai (2013), examine the theoretical background and models employed in the study of games and simulations. They focus principally on the theories of cognitivism, constructivism, enactivism, and the socio-cultural perspective. Results indicate that although cognitivism and constructivism are the major theoretical foundations employed by game-based science learning researchers, enactivism and the socio-cultural perspective are the emerging theoretical paradigms drawing increasing attention in this field. This literature review indicates an increasing recognition of the effectiveness of digital games in promoting scientific knowledge and concept learning, while giving lesser importance to facilitation of problem-solving skills, exploring outcomes from the viewpoint of scientific processes, affect, engagement and socio-contextual learning. This view is echoed by other researchers, such as Warren, (2016), who systematically review and demonstrate the effectiveness of simulation games on satisfaction, knowledge, attitudes, skills and learning outcomes within nurse practitioner programmes. After comparing online simulation-based learning with traditional lectures, they find an increase in student knowledge and confidence when using simulation games. Peterson (2010) also performs a meta-analysis, examining the use of computerised games and simulations in language education from a psycholinguistic and socio-cultural viewpoint. Results show valuable opportunities for effective language learning, confirming that games are beneficial in helping students learn another language.

Sitzmann (2011), using interactive cognitive complexity theory, offers a comparative review on the instructional effectiveness of computer simulations. To perform the review, she examines three affective outcomes (motivation, effort, and self-efficacy), one behavioural (effort), two cognitive (declarative knowledge and retention), and two skill-based learning outcomes (procedural knowledge and transfer). She concludes that, post-training, simulation-trained learners demonstrate higher self-efficacy and procedural knowledge. Furthermore, she highlights the significance of using specific methods to improve simulation learning, namely, integration of game use within an instructional programme, high level of learner activity, no gaming time limit, and adopting the simulation game as a supplement to other methods, which is inconsistent with Wouters et al.s survey (2013). Hsu et al. (2012) provide a cross-analysed content analysis agreeing with the previous researchers that topics such as "Motivation, Perceptions and Attitudes" are of utmost importance. 
In a recent review of business literature, Carenys and Moya (2016) discuss the impact of digital game-based learning (DGBL) on students. They examine DGBL both from a theoretical point of view and on a practical basis through three stages: a) the evaluation of digital games in the preparatory stage, b) specifying which research has been deemed appropriate for DGBL deployment, and c) the learning outcomes (cognitive, behavioural, affective, and multi-dimensional) that can be attained through digital games. This study moved current research forward in understanding the effectiveness of digital games and advanced the use of digital games in the classroom.

A variety of meta-analyses and systematic reviews have examined the implementation of games and simulations in the learning process, either as a main course element or as a supplement to conventional lectures, illustrating the ever increasing interest of researchers in this promising field.

\section{Synthesis of previous reviews/meta-analyses}

After studying the previous reviews, it is evident that the most commonly referred games in past reviews are digital and computerized games (Sitzmann, 2011; Young et al., 2012; Smetana \& Bell, 2012; Girard et al., 2013; Merchant et al., 2014; Clark et al., 2015; Carenys \& Moya, 2016; Warren et al., 2016). The technological revolution and the invasion of Internet in Higher Education urge students to build digital and collaborative skills for the twenty-first century through gaming. Also, the emergence of a participatory culture in education spurs researchers to get involved with digital games and simulations. Other games mentioned are serious games and their impact on the learning process (Connolly et al., 2012; Bellotti et al., 2013; Backlund \& Hendrix, 2013; Wouters et al., 2013; Tsekleves et al., 2014; Fu et al., 2016). The researchers refer to serious games since they are basically considered as games with educational orientation and not with just entertaining ones.

Another important element we have identified is whether games should be fully or partially integrated into the learning process. Most of the researchers agree that games should be treated mainly as supplementary elements (Sitzmann, 2011) since full integration requires high-quality mechanisms, students' engagement, and instructors' support. In other cases, the integration of games in the curriculum could either function as a supplement to existing teaching techniques or as a partial substitute for traditional teaching methods (Rutten et al., 2012). Moreover, games could even be fully integrated for achieving better learning outcomes (Lameras et al., 2016) because games add diversity in educational teaching modules. Nevertheless, the integration of games depends on instructors' contribution and the way they design and incorporate games in their teaching. This means that instructors should be equipped with knowledge and experience, and be aware of providing guidance to students as regards the proper way of playing games.

The beneficial contribution of game-based learning is broadly identified by the majority of previous reviewers, especially regarding cognitive outcomes. Results indicate that games can be as effective as traditional learning modes, revealing their effectiveness in promoting knowledge acquisition (Smetana \& Bell, 2012; Backlund \& Hendrix, 2013; Clark et al., 2015; Warren et al., 2016), as well as content understanding and concept learning (Connoly et al., 2012; Li \& Tsai, 2013; Fu et al., 2016). Additionally, students achieve their learning goals through playfulness and problem-based learning (Tsekleves et 
al., 2014), thus leading to self-efficacy and transfer of learning (Gegenfurtner et al., 2014).

Another substantial impact emerged is the effectiveness of games not only in the cognitive domain but also in the affective and behavioural domains (Ritzhaupt et al., 2014; Shin et al., 2015; Tsekleves et al., 2014; Fu et al., 2016; Carenys \& Moya, 2016). The affective domain is thoroughly discussed by the reviewers. In particular, games influence students' motivation, engagement, and satisfaction of the game-based learning. Regarding behavioural outcomes, few reviews have been conducted, showing that games offer a plethora of opportunities for collaborative learning, enhance interactivity and feedback among players, and develop social and soft skills as well. Some other studies contradict these findings, in a way that they do not reveal positive effects of games (Young et al., 2012; Girard et al., 2013; Merchant et al., 2014), or reveal a rather neutral effect (de Smale et al., 2015). In these reviews, games and simulations appear to have some or no positive effects on knowledge and skills acquisition when comparing with traditional instructional methods.

\section{Research method}

\section{Research selection}

The authors developed a pre-defined review protocol to answer the research questions, specifically aimed at minimising researcher bias. The literature review was carried out between July and October 2016 and followed the design stages described below.

The reviewed papers are identified through keywords in referenced electronic databases, such as Google Scholar, Web of Science, ERIC, PsycInfo, PsycArticles Fulltext Search, InterDok, ProQuest, Scopus, BEI, and SearchPlus. The keywords for learning outcomes are a combination of the term games or simulations paired with the term higher education, employing the Boolean operator "AND”. Additional keywords for learning outcomes are learning objectives, learning goals, learning objectives and effects. Keywords for platform and delivery methods include computer-based, web-based, digital, virtual, online, and technology. Keywords for games and simulations are educational games, business simulations, role-playing simulations, game-based learning, video games, and serious games. Moreover, the Boolean operator "OR" is employed to combine all these keywords. The study sets the broadest range of keywords, so as not to limit the scope of related articles.

Furthermore, the researchers conducted a comprehensive database search in bibliographic indices for the data selection. The search is related to a variety of scientific fields of study, including Education, Psychology, Information Technology, Management, and other scientific areas (e.g., Engineering, STEM, Health, etc).

\section{Assessment and extraction}

The dataset consists of journal articles referring to games, simulations or learning in their title and/or abstract. The researchers piloted and evaluated their selection criteria based on prior studies. The study selection process was conducted in two separate phases: a) the researchers, working independently, initially, and, subsequently, together, screened the titles and abstracts for inclusion criteria, and b) in the event of disagreement or insufficient information, they carried out a thorough consideration of the body of the 
articles (i.e. methodology and results), again independently, first, and, then, together, resulting in consensus. Then, whether to include the text or not was discussed, based on pre-determined criteria. The inclusion criteria used are as follows:

- Only empirical articles across a variety of study designs may be included, so as to achieve rich data.

- The participants should be over the age of 18 (e.g., students in higher education, college students, instructors, etc.)

- Articles that provide an evaluation of student learning outcomes (via the use of games for pedagogical purposes) may also be included.

- The resources should, mainly, consist of journal articles and conference papers, which, due to the peer review process, ensure a high quality of material to examine. Existing meta-analysis and systematic literature reviews should be included as well, in order to cross-validate the review findings.

- The articles should be available in either English or French.

- The articles should adhere to the objective of the study and the definition of the terms games and simulations as pedagogical applications.

- Studies containing samples from higher education institutions should also be included. Conversely, research on the effects of games in primary or secondary education should be discarded.

- The review should include games and simulations used in traditional, as well as in online environments.

- Only peer-reviewed journal articles published between 2010 and 2016 should be included, as the intention is to include the most current research.

- Several exclusion criteria, listed below, were also applied in this study:

- Non-empirical studies or studies which solely describe the design of a learning environment.

- Participants who are younger than 18 years old.

- Non-GBL tools and entertainment games.

- Book chapters -not only are books difficult to search for on databases, they are, also, hard to access as full texts. Additionally, books are not always subject to the same peer review process as scientific articles. Dissertations, theses, editorials, book reviews and reports are also excluded for similar reasons.

- Articles that cannot be accessed as full texts are excluded.

- Articles that do not match the research objectives.

- Research focused on types of education other than higher education.

- As mentioned above, articles published before 2010.

The following figure illustrates the inclusion and exclusion criteria (Fig. 2):

Application of these criteria resulted in an initial dataset, yielding 8859 studies, published between 2010 and 2016. The selected papers are derived from 67 academic journals representing a variety of disciplines. Most papers come from the scientific journal "Computers \& Education", while "British Journal of Educational Technology", and "Simulation \& Gaming" were the next two journals appearing with the most frequency. In the final stage, several meetings were organized between researchers to discuss the findings, and to decide on presentation. 


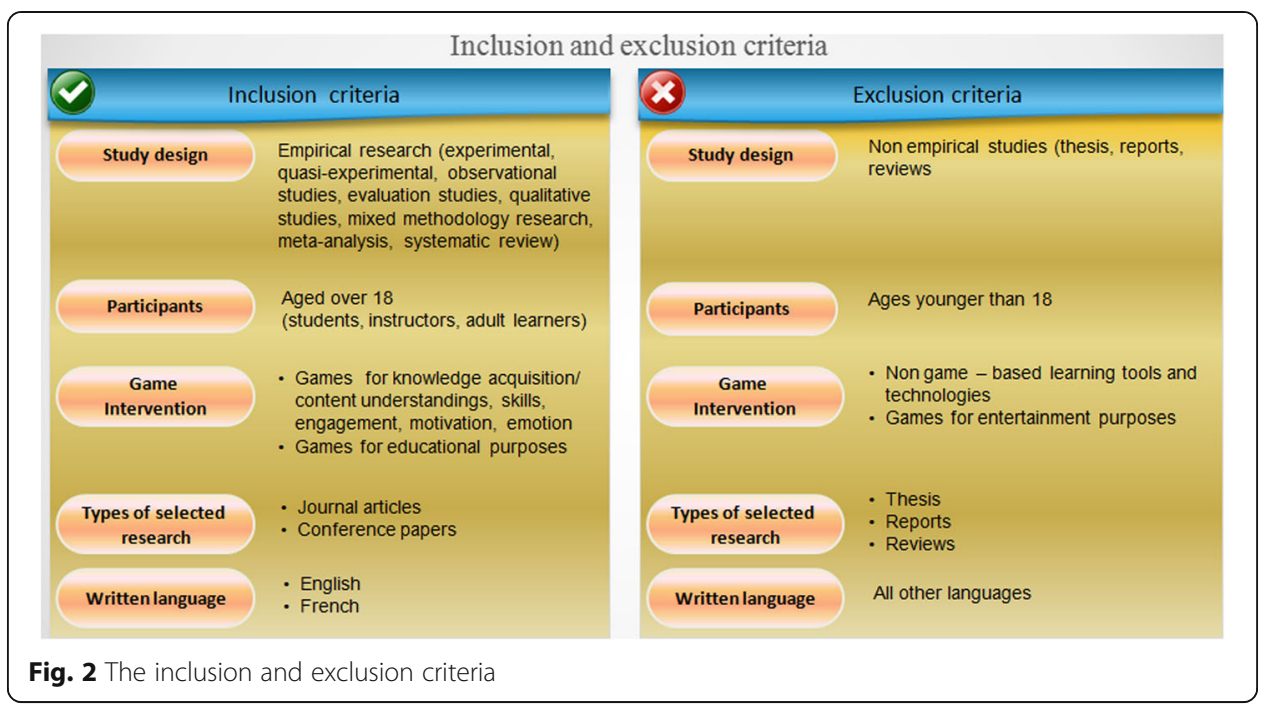

The results show a steady increase in published papers discussing games from 2012 onwards. After systematically reviewing their abstracts, a final shortlist of 628 potential full text articles emerged. Two hundred and seventeen out of the 628 were excluded, primarily, due to undesirable focus (e.g. theoretical scenarios for using simulations in education). For each of the remaining 411 studies, the researchers identified and recorded some basic themes, for example, types of learning outcomes, effect or impact of game and simulation methods on learning goals, participants and settings, research questions, research methodology and results. Of these, 123 papers, which are found to contribute data, are selected for the review, whereas the remaining 288 articles are excluded, due to the fact that they are written in a language that the researchers do not understand, or because they are focused on a field other than higher education. The majority of these articles are published in scientific journals or conference proceedings, whereas 25 studies are either meta-analyses and/or systematic reviews. An outline of the entire review is depicted in the following figure (Fig. 3):

\section{Data analysis and synthesis}

The identified articles are analysed using a qualitative content analysis technique, which leads to a coding scheme, including a main category, three sub-categories and several associated topics related to the main categories. The researchers unanimously agree upon the coding that emerged from the analysis of the reviewed papers. To ensure inter-rater reliability (p) with respect to the quality of article coding procedures, a small random sample $(n=20)$ of the selected articles is coded in duplicate. The calculated reliability exceeds $93 \%$, which is a high quality of agreement across coding categories. Furthermore, a review of mixed-methodology studies provides high-quality evidence, due to a combination of quantitative and qualitative elements in terms of methodological triangulation.

The researchers examined the studies from varying viewpoints. Firstly, they analysed the data set characteristics, such as the continent on which the studies are conducted, the subject discipline, the methodological research design, the types of games and 


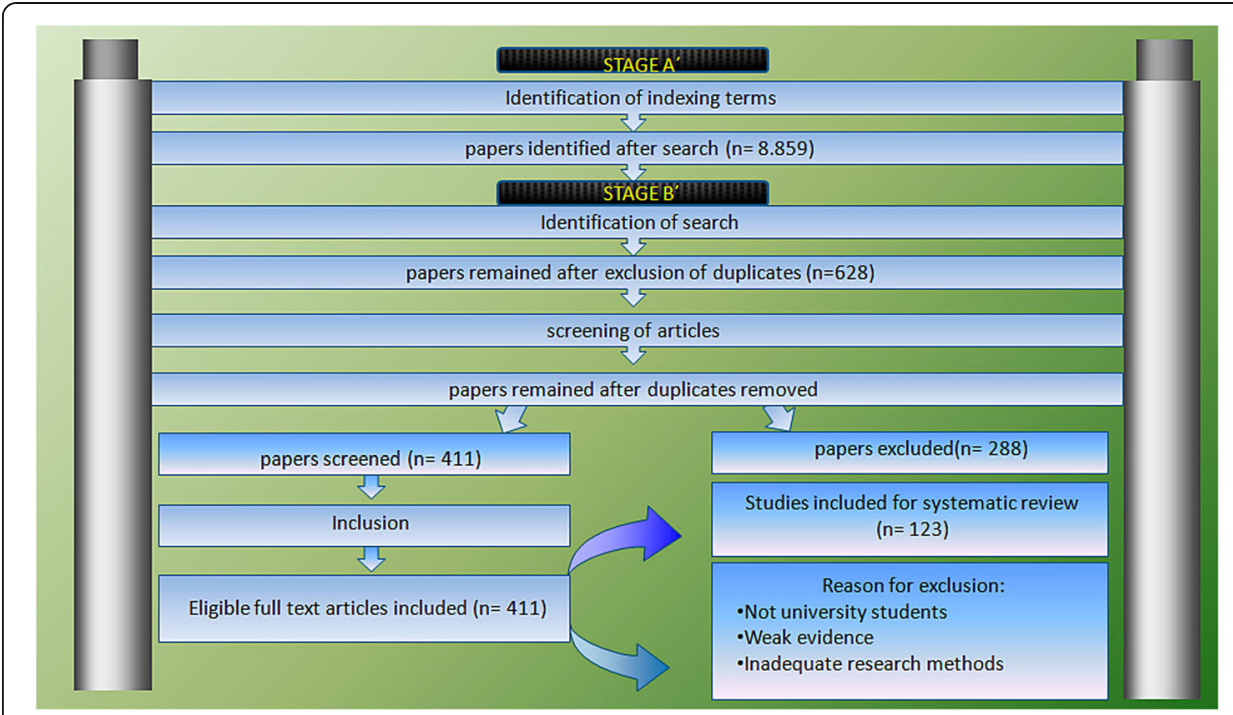

Fig. 3 Research review methodological scheme

simulations identified, and the time period in which the majority of the studies took place. The emphasis is on the analysis, measures, and design of the quantitative methodology (experimental, quasi-experimental, pre-test, post-test surveys, etc.), as well as the qualitative methods used in the reviewed surveys.

To sum up, the review studies are selected through a systematic process with pre-arranged criteria. There is no intended bias applied to the selected studies, and although the majority of studies come from Europe, this is simply the result of the systematic selection process.

\section{Results}

\section{Data set characteristics}

When analysing the data, the researchers came across some interesting characteristics. Other than the meta-analytic studies and review research, the locations of the remaining surveys are as follows: 33\% conducted in Europe, 22\% in Asia, and 18\% in the USA, whereas $24 \%$ of the articles do not directly mention a location (Fig. 4). Most of the articles come from the USA, the UK, and the Netherlands.

With respect to genre, there is a diverse representation of games and simulations. The most prominent game genre identified in the relevant literature seems to be simulation games in general, that is to say, virtual/online games or simulations, computer-based learning, role-playing games, serious games, and business simulation games. This representation is illustrated below (Fig. 5):

With respect to the busiest publication period, the majority of studies that meet the inclusion criteria were published between 2013 and 2016, as shown in the following bar chart (Fig. 6). This finding demonstrates a notable trend amongst researchers discussing the topic of games and simulations in recent years, due to increased awareness of the use of technological games in higher education.

The data also represents a wide range of subject areas. Some cover multiple areas, for example Engineering, Management, Science, Law, Social Sciences and Humanities 


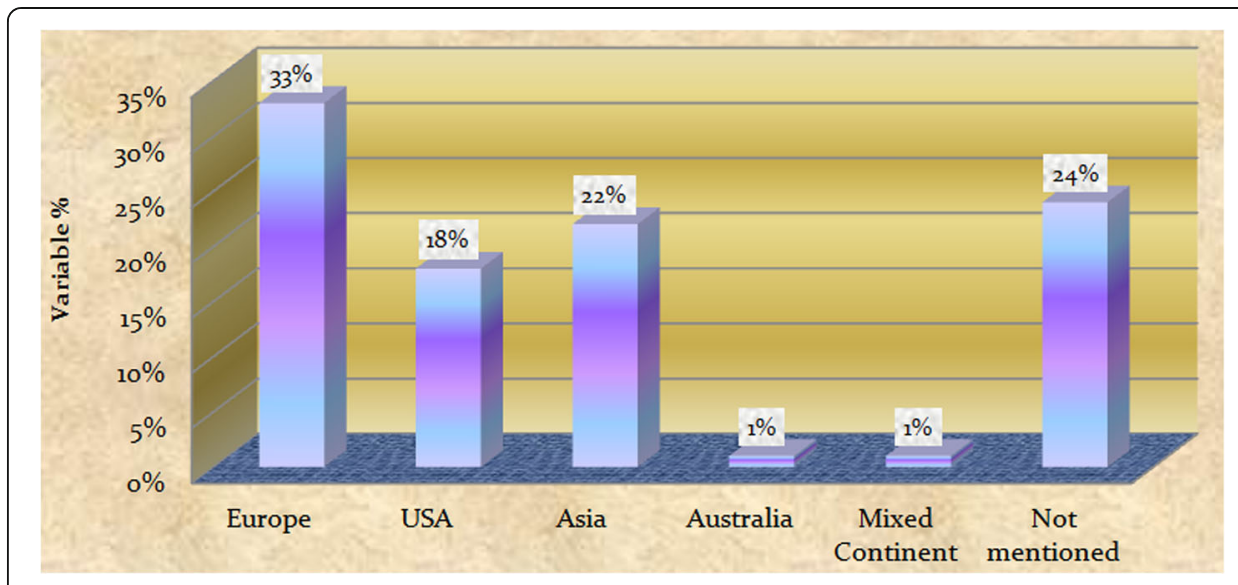

Fig. 4 Continets where studies are conducted

(Tao et al., 2015), or even just two areas, such as Biology and Computer Sciences (Yang \& Chang, 2013), while others refer to only one academic discipline. The subject areas are sorted into larger categories, with the most common area being Business Management and Marketing. The results are shown in the figure below (Fig. 7):

The reviewed articles include data from 99 samples and 20,406 participants, which is a considerably large grouping. The population tested in the literature review ranges from 5 participants in small qualitative studies (Ke et al., 2015) to 5071 participants in extensive quantitative quasi-experimental research (Lu et al., 2014). Most of the participants are young undergraduate, graduate or post-graduate students, and faculty members. The studies consistently indicate a good gender balance in participants. In some studies, there is both student and faculty participation (Kapralos et al., 2011; Felicia, 2011; Hess \& Gunter, 2013; Hämäläinen \& Oksanen, 2014; Beuk, 2015; Crocco, 2016), whereas in others, only instructors are chosen as participants (Tanner, 2012; Badea, 2015; Franciosi, 2016). On the whole, most studies use students as participants.

\section{Procedures and research methodologies}

Most studies use either an experimental or a quasi-experimental design employing a pre-test and/or a post-test evaluation, with four using only a pre-test questionnaire,

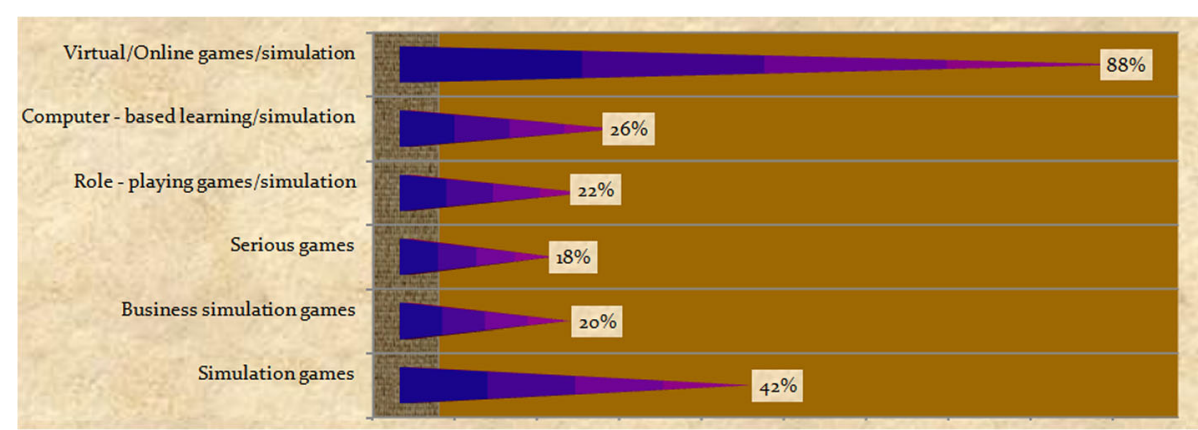

Fig. 5 Representation of the game genres 


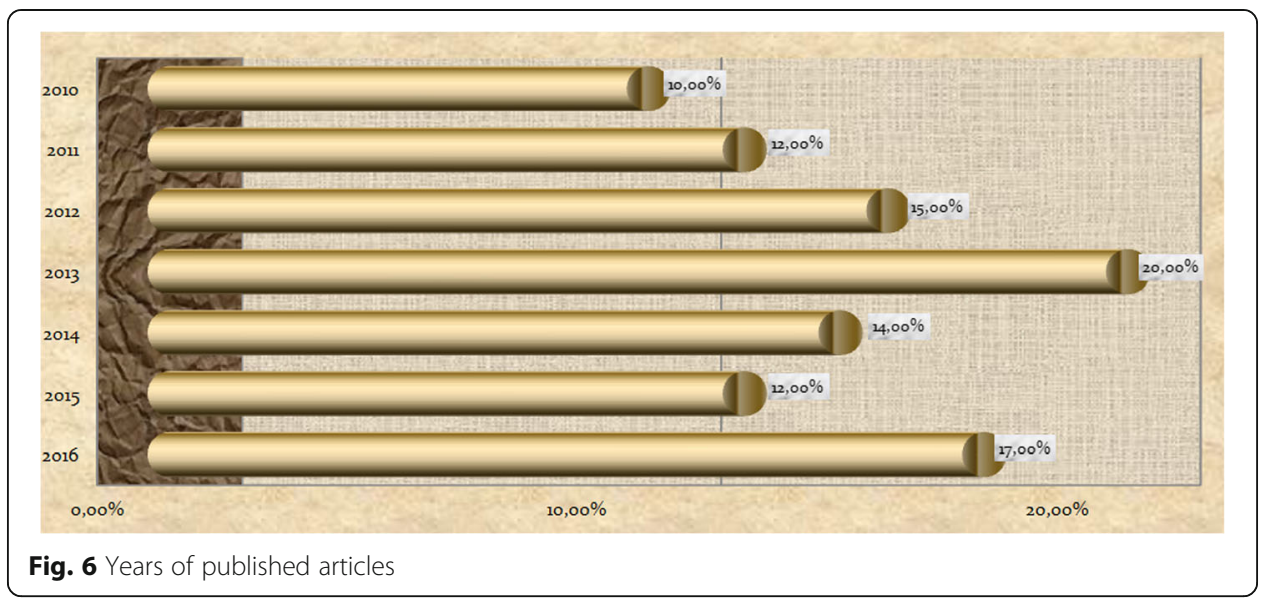

and six using only post-test evaluations. The effects of games and simulations on learning outcomes are measured through calculating the difference between pre-test and post-test scores of the experimental or quasi-experimental design. More specifically, the researchers compare the increases in scores between control and experimental groups to evaluate the effectiveness of using the tested games and simulations. The studies include longitudinal surveys (e.g. Hainey, 2011) conducted for a specified number of years, whereas others are comparative studies (e.g., Boeker, 2013; Poikela, 2015).

Researchers use quantitative methods in the majority of studies (68.6\%), while13.1\% use qualitative methodology. Some studies follow a mixed research methodology (nearly 18.2\%), providing pragmatic perceptions and methodological triangulation of the results. The measures utilized in quantitative studies include knowledge questionnaires, as well as academic, evaluation, and cognitive tests, while in qualitative studies the methods used include interviews, case studies, observations and focus groups.

The studies portray a variety of time periods spent playing games and simulations: some of the participants interact with games over a single session, while others are involved in the gaming process for several weeks or even months (e.g., Yang \& Chang, 2013; Woo, 2014). The studies include multi-player games (e.g., Silvia, 2012; Yin, 2013), as well as single-player games.

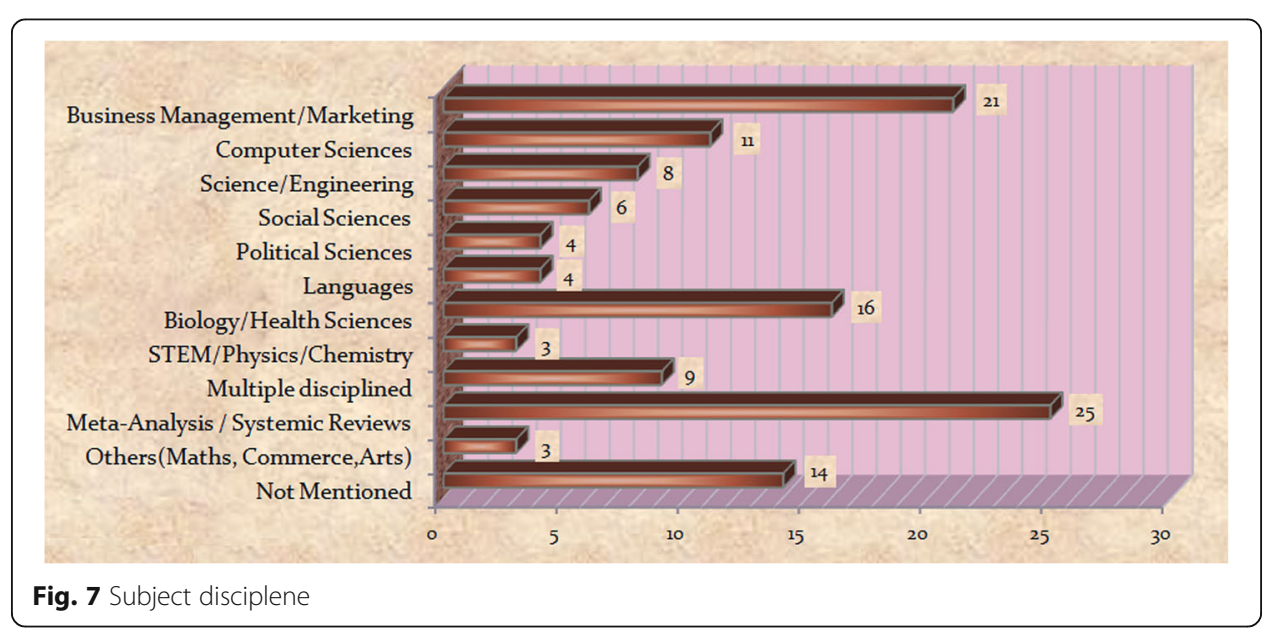




\section{Learning outcomes of games and simulations}

In the present review, keeping in mind the aforementioned research questions (p.3), the researchers break down their findings in relation to the learning outcomes of games and simulations into three categories, namely cognitive, behavioural, and affective outcomes. A map of the emerging concepts, which will be further discussed, is illustrated below (Fig. 8):

\section{Cognitive outcomes}

Many reviewed studies discuss the impact of GBL activities in learner knowledge acquisition and conceptual understanding (Hainey et al., 2011; Connolly et al., 2012; Fu et al., 2016; Geithner \& Menzel, 2016). There has been an impact evaluation across subject disciplines, such as Computer Science (Strycker, 2016), Engineering (Chaves et al., 2015), Physics (Adams, 2016), Medicine (Dankbaar, 2016), Nursing (Sarabia-Cobo, 2016), Management (Geithner \& Menzel, 2016), Political Sciences (Jones \& Bursens, 2015), Education (Ke, 2015), Languages (Franciosi, 2016), and Social Sciences (CózarGutiérrez \& Sáez-López, 2016).

\section{Knowledge acquisition}

Cognitive outcomes refer "to the knowledge structures relevant to perceiving games as artefacts for linking knowledge-oriented activities with cognitive outcomes" (Lameras et al., 2016, p. 10). Tasks framed as games and simulations are deployed to develop a diverse range of cognitive skills, such as deep learning (Vos \& Brennan, 2010; Young et al., 2012; Erhel \& Jamet, 2013; Crocco et al., 2016), critical thinking and scientific reasoning (Beckem \& Watkins, 2012; Halpern et al., 2012; Ahmad, 2013), action-directed learning (Lu et al., 2014), transformative learning (Kleinheskel, 2014), decision-making (Tiwari, 2014), knowledge acquisition and content understanding (Terzidou, 2012; Elias, 2014; Fu et al., 2016), spatial abilities (Adams et al., 2016), and problem solving (Liu, 2011; Lancaster, 2014).

The effect of games and simulations on learning remains a controversial issue amongst researchers in the field, as it will be further confirmed in this article. Some reviewed studies indicate improved learning, while others show no positive effect on knowledge and skill acquisition compared to traditional learning methods. The value of simulations can be examined from the perspective of content change as discussed in Kovalic and Kuo's study (2012). Simulations are directly linked to the course content and students are given the opportunity to apply and better understand theoretical

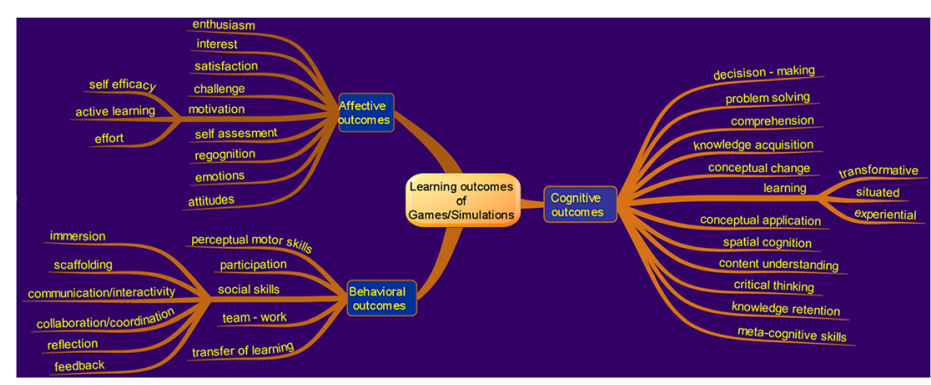

Fig. 8 Learning outcomes of Games/Simulations 
concepts. Additionally, simulations provide an environment in which students can experiment with different strategies, adopt different roles, and take charge of their own decisions by assuming responsibility. The latter issue is discussed at length by Liu et al. (2011), who find that, when solving problems, students are more likely to learn via playing a game than via a traditional learning experience.

Serious gaming, especially given the context of enthusiastic students, has proved to be an effective training method in domains such as medical education, for example, in clinical decision-making and patient interaction (de Wit-Zuurendonk \& Oei, 2011). Similarly, Kleinheskel (2014) illustrates the importance of designing self-reflective simulating activities for nursing students, and aligning such design with cognitive outcomes. When students self-reflect on simulated clinical experiences, they add to their existing knowledge, and apply new knowledge to transformative learning. Poikela et al. (2015), in a simulated nursing procedure, compare a computer-based simulation with a lecture to examine the meaningful learning students may achieve via the two teaching methods. They conclude that students who participate in the computer simulation are more likely to report meaningful learning outcomes than those taking the lecture, due to the strong presence of reflection-based activities and metacognitive themes. Similar results are present in Chen, (2015), survey in which both solitary players and collaborative groups achieve equally positive learning outcomes in a game. Students significantly improve judging by their pre- and post-test assessments, which indicates that the gaming experience affects their overall performance, and, most likely, promotes conceptual understanding. Moreover, collaborative GBL allows students to re-construct and co-construct knowledge, thus encouraging problem-solving through peer discussion.

Challenging games enhance participant performance (Wang \& Chen, 2010; Gold, 2016). This finding is supported by von Wangenheim, (2012), who analyse the cognitive dimension of an educational game focusing on memory, understanding and conceptual application. The validity of micro-simulation games is identified by participants in Lukosch, (2016), research who evaluate a specific microgame as an excellent instrument for enhancing situated and experiential learning by transferring knowledge to an actual situation at the workplace. The results comply with those of Riemer and Schrader (2015), where the application of comprehension and transfer of knowledge are best achieved using simulations.

Furthermore, the impact of game-based learning on learning performance has been observed by numerous researchers across diverse subjects, as reported above (Zacharia \& Olympiou, 2011; Rutten et al., 2012; Beckem \& Watkins, 2012; Boeker et al., 2013; Shin et al., 2015; Hou, 2015; Chen et al., 2015; Tao et al., 2015). For instance, Divjak and Tomić (2011) provide evidence that computer games impact mathematical learning, revealing the positive effect of games on student learning outcomes. Reviews by Young et al. (2012) confirm the effectiveness of using videogames on History, Languages, and Physical Education. The analysis of four experimental virtual conditions in pre- and post-test assessments reveal that virtual experimentation promotes conceptual understanding in Physics students (Zacharia \& Olympiou, 2011). A 3D visualisation and simulation laboratory activity on protein structure is more effective than traditional instruction modules, as described in White, (2010), research resulting in students preferring to work with visualized simulations. 
Simulation games also positively affect clinical practice situations. "The Ward", a simulation game in Stanley and Latimer's (2011) research proves to be an enjoyable and valuable learning tool in addressing clinical skill practice, nursing practice knowledge, critical thinking and decision-making. Vos and Brennan (2010) highlight the effectiveness of marketing simulation games, where students perceive simulations as an enjoyable learning approach, contributing to decision-making, as well as other valuable knowledge and skills, a finding consistent with Tiwari et al. (2014) survey. Swanson et al. (2011) created a rubric to measure the effectiveness of teaching strategies in nursing education. The experimental post-test assessment survey aims to evaluate the effects of three teaching strategies on the outcome of performance and retention of intervention activities, student satisfaction, self-confidence and practical educational preferences. Results reveal significantly higher retention scores compared to the first assessment, indicating that high scores in the improved rubric are related to the interactivity of the simulation scenario.

Nevertheless, it should not be taken for granted that students consistently prefer virtual learning settings to more traditional face-to-face environments (Hummel et al., 2011). Serious games concerning cognitive perceptions show varying results. For example, simulations are shown to support the comprehension and application of knowledge, albeit less effectively than quizzes and adventures (Riemer \& Schrader, 2015). In Fu et al. (2016) review, despite GBL providing a motivating and enjoyable experience, there is a lack of strong evidence to show that games lead to effective learning outcomes. In some cases, there is inconsistency in student views regarding the integration of online games as a positive learning method (Bolliger, 2015). Similar views are supported by some researchers, who acknowledge students' and educators' hesitation towards virtual simulations and serious games, but they insist on the inclusion of games into course material, and on instructors' familiarization with their use (Kapralos et al., 2011).

\section{Perceptual skills}

Other studies confirm the power of games and simulations in developing cognition abilities, especially in the instances of virtual simulations enhancing complex cognitive skills (Helle et al., 2011; Siewiorek, 2013), such as self-assessment (Arias Aranda, 2010), or higher-order thinking (Crocco et al., 2016). These are meta-cognitive skills, regarded as essential elements of in-depth learning. The incorporation of game mechanisms into simulations is widely recognised by researchers as beneficial, especially regarding laboratory tasks, where simulation scenarios urge students towards problem-solving and, reflection, thus achieving metacognitive outcomes (Hou \& Li, 2014; Hou, 2015). Kikot, (2013) concur with the above researchers, stating that students perceive simulation-based learning (SBL) environments positively when asked to achieve dynamic learning outcomes, including thinking, interpreting, and associative skills.

Silvia (2012) also references cognitive and metacognitive outcomes derived from a multi-role simulation. The simulation helps students apply the concepts they learn in class by connecting the theoretical issues with real-world situations, thus developing their analytical skills, and through comparing different viewpoints, which leads to enhanced critical thinking. Students use the interactive nature of simulations to develop arguments, make judgements and evaluate situations. More importantly, simulations 
encourage students to develop self-awareness. Similarly, Cela-Ranilla, (2014) conducted a study in which students display a tendency to perform better in analytical work, such as monitoring, planning and assessment rather than in action-based work. Wouters et al. (2013), on the other hand, find serious games to be more effective in terms of learning and retention.

Learners can also actively participate in a web-based simulation to facilitate immersion and reflection, leading to deeper understanding of the content (Helle et al., 2011). A simulation framework can facilitate learning in terms of flow experience and learning strategies. Indeed, in a study conducted by Li, Cheng, and Liu (2013), the framework helps students lacking background knowledge to balance challenge and skill perceptions, while for students with average to advanced levels of knowledge, it facilitates the learning experience by either reducing the challenge perception or promoting the skill perception. Along the same lines, Pasin and Giroux (2011), analyse the mistakes students make in simulations using an empirical prototype. Results show that, although simple decision-making skills are easily acquired through conventional teaching methods, simulation games are useful tools for mastering managerial skills, such as complex and dynamic decision-making. Lin and $\mathrm{Tu}$ (2012) also confirm that simulations enable students to train themselves in decision-making.

\section{Instructors' engagement}

Students are challenged to develop interpersonal, analytical and creative skills, discouraging absenteeism, feelings of boredom and reluctance, leading to academic achievement. However, simulations not only exhibit positive effects in the learning experience of the student, but, also, do so for instructors, as well, in the context of teaching experience. For academics, simulations raise the level of performance, encouraging students to be more alert and attentive during class activities (Navidad, 2013), and thus to achieve better learning outcomes. In this vein, instructors are urged to design simulations to be as challenging as possible to stimulate student interest in interacting with the simulation as well as with their peers. Felicia (2011) denotes that instructors agree with students in acknowledging the educational benefits of video games, such as an understanding of difficult concepts, improvement of spatial awareness and analytical skills, critical thinking, and problem-solving strategies. To enable them to do so, instructors emphasize the importance of clearly expressed learning goals to guide students when using simulations in an online instructional technology course (Kovalik \& Kuo, 2012).

Even setting aside the potential learning benefits derived from participation in GBL, a stronger connection between games and curricula remains to be forged, as well as the application of more dynamic academic challenges, so as to better adapt to the knowledge of diverse learners (Pløhn, 2013). Following such reasoning, as indicated in the literature, faculty plays a key role in achieving learning goals via the use of games and simulations. The instructor role correlates with the demand for abstract learning concepts. In their meta-analysis, Wouters and Van Oostendorp (2013) show how instructors, acting in a facilitating and supporting role, can foster learning, particularly in selecting and discussing new information and where higher order skills are involved in the learning outcomes. Similarly, instructors can monitor student behaviour and evaluate not only the capabilities, but also the attitudes of tomorrow's higher education 
managers during the decision-making process. Rutten et al. (2012) focus in their literature review on the level of instructional support in GBL, and suggest that a pedagogical framework for the application of computer simulations in education requires a corresponding integration of the educator's role.

\section{Behavioural outcomes}

Behavioural objectives for higher education students refer to the enhancement of teamwork and improvement in relational abilities (Ranchhod, 2014), as well as stronger organisational skills, adaptability and the ability to resolve conflicts (Vos \& Brennan, 2010).

\section{Social skills/teamwork}

Simulation games are often seen as powerful tools in promoting teamwork and team dynamics (Stanley \& Latimer, 2011; Tiwari et al., 2014; Lin, 2016; Wang, 2016), collaboration (Hanning, 2012), social and emotional skills (Ahmad et al., 2013), and other soft skills, including project management, self-reflection, and leadership skills (Siewiorek, 2012; Wang et al., 2016), which are acquired through a reality-based scenarios with action-oriented activities (Geithner \& Menzel, 2016).

In a Spanish management course, simulations enabled students to build pivotal capacities, such as management abilities and team working to enable the success of future managers (Arias Aranda et al., 2010). A computer simulation at a university in Taiwan led to comparatively higher learning gains against traditional teaching through collaborative laboratory activities (Shieh, 2010), by facilitating students to carry out more active learning and improving their conceptual understanding. Simulation scenarios provide improved social and communication skills, which lead to the enhancement of student knowledge (Sarabia-Cobo et al., 2016).

Additionally, collaboration is considered an essential element in the learning process (Elias, 2014). The findings of Hummel et al. (2011) reveal that serious online games improve the quality of learning when it comes to problem-based situations in the workplace by using active collaboration. For this reason, faculty members are urged to create learning environments to support active participation by students in the educational process. Moreover, according to the constructivist approach, the instructor's role is a significant factor in empowering groups to construct knowledge in a collaborative manner (Hämäläinen \& Oksanen, 2014). The instructors engage higher education students in the process of formulating hypotheses, interpreting context, providing explanations, and describing observations, by designing and implementing a collaborative and interactive GBL environment. In Yin et al.'s study (2013), students react positively to participatory simulations, due to the belief that the system helps them advance their conceptual understanding effectively through scaffolding, discussion, and reflection. Participants in Cózar-Gutiérrez and Sáez-López's study (2016), while stating that video games are non-essential tools in an educational context, nevertheless, value GBL as an immersive environment that facilitates increased activity and student engagement.

Teamwork, however, seems to be a controversial issue in Costa, (2014) which evaluates improvement of knowledge sharing. Some learners consider teamwork as a means to facilitate decision making in a game, while others express dissatisfaction due to their peers, be it the latter's reluctance to take on responsibility or poor negotiation 
capabilities. Research by Bolliger et al. (2015) similarly indicates that some learners remain hesitant, as they feel the use of games may actually decrease opportunities for communication with peers and instructors. Merchant et al. (2014) conclude that student performance is enhanced when playing individually rather than in a group.

\section{Interaction and feedback}

In GBL methods, meaningful feedback is a key factor in students achieving the objectives, as well as in being encouraged to reflect on misunderstandings and to transfer learning to new educational contexts (Swanson et al., 2011). In the current study, the scope is to investigate learner-learner interaction and social feedback through game mechanics. Higher education students evaluate games and simulations focusing on behavioural change and improvement of interactive abilities. The computer game DELIVER! for example, is evaluated very positively by students due to its focus on active student participation and overall positive impact on social interaction (von Wangenheim et al., 2012). Simulations provide visual feedback, encouraging active exploration of the student's own understanding, enabling a move beyond knowing-in action and beginning to reflect-on and in-action during training, resulting in the contextual application of prior knowledge (Söderström, 2014). Real-time feedback in simulation games enables students to clearly define the objectives and expectations in the interactive environment, leading to a reduction in anxiety and uncertainty, thus encouraging better performance (Nkhoma et al., 2014).

The literature extensively documents the interaction between behavioural outcomes, learning performance and communication especially in Online Distance Learning (ODL). Indeed, regular feedback on student performance during DGBL facilitates deep learning (Erhel \& Jamet, 2013). A survey conducted by Chen, (2010) shows that online games can be social and interactive technologies, helping students form friendships with their peers and providing multiple types of interaction.

Ke et al. (2015) stress the importance of player interaction, indicating that the inherent interaction between players and their gaming-situated learning environment supplies structured challenges and feedback. Huang, (2010) share the same view, confirming that, due to the necessity of receiving feedback from peers and the game itself, increased interaction opportunities arise in game-play, adding that interaction is a decisive factor in the construction of knowledge (Seng \& Yatim, 2014). In a survey conducted by Denholm et al. (2012), students report improved team working through the use of serious games. They attribute this to receiving feedback, and stressing that even conflict is often considered valuable as it brings diverse views to the fore.

To conclude, the main body of literature explores the impact of games and simulations on learning outcomes on the behavioural level, especially when students are involved in interactive and participatory simulation tasks. The majority of studies reveal a positive effect on behavioural outcomes, concluding that students benefit from appropriate feedback, and reflection through game-based communication activities.

\section{Affective outcomes}

Many studies highlight the affective outcomes of using games and simulations in the learning process. The majority of them includes student engagement (Auman, 2011; Hainey et al., 2011; Lin \& Tu, 2012; Kikot et al., 2013; Lu et al., 2014; Ke et al., 2015), 
motivation (Liu et al., 2011; Liao \& Wang, 2011; Costa et al., 2014; Lukosch et al., 2016), and satisfaction (Cvetić et al., 2013; Dzeng, 2014; Lancaster, 2014; Sarabia-Cobo et al., 2016).

\section{Motivation and engagement}

Engagement and motivation are major factors in enhancing higher education learning objectives (Connolly et al., 2012; Erhel \& Jamet, 2013; Ke et al., 2015; Nadolny \& Halabi, 2015). Motivation is considered a central factor in the majority of reviewed studies (Felicia, 2011; Ljungkvist \& Mozelius, 2012; von Wangenheim et al., 2012; Bellotti et al., 2013; Hannig et al., 2013; Ahmad et al., 2013; Pløhn, 2013; Li et al., 2013; Denholm et al., 2012; Dzeng et al., 2014; Lancaster, 2014; Ariffin et al., 2014; Bolliger et al., 2015; Cózar-Gutiérrez, \& Sáez-López, 2016; Dankbaar et al., 2016; Fu et al., 2016). Some results suggest the effectiveness of GBL in motivating and achieving learning goals can be found at the lower levels of Bloom's taxonomy (e.g. Connolly et al., 2012). In the context of digital SBL environments, other motivational dimensions are highlighted, such as self-efficacy (Sitzmann, 2011), in conjunction with the transfer of learning (Gegenfurtner et al., 2014).

Motivation is a combination of elements such as attention, relevance, confidence, and satisfaction, which can increase germane cognitive loads. Chang, (2010) examine the effects of motivation in an instructional simulation game, called SIMPLE. According to the post-game evaluation, student motivation comes from peer learning and user cooperation. Moreover, when instructors teach strategy, this enhances student motivation and engagement, encouraging acceptance of the game, and leading to stronger interest in course-directed learning. Thus, teachers should create a flexible learning environment, giving due consideration to peer interaction, learning motivation, pedagogical support and encouragement to help students develop their autonomy and retain an interest in learning.

Another important element contributing to affective outcomes is challenge. Hainey et al. (2011) find the presence of a challenge to be the top ranked motivation for online game players, while recognition is the lowest ranked motivation regardless of gender or amount of players in the game. Gamers in a multiplayer environment tend to report competition, cooperation, recognition, fantasy and curiosity when playing games, while online players experience challenge, cooperation, recognition and control. By contrast, fanatical computer game players experience disappointment and a lack of challenge, as they tend to value the technical aspect over the challenges presented by game play. In Hess and Gunter's survey (2013), students in a game-based course are motivated, because of the positive social interaction they experience while playing the game; this intrinsic motivation is positively correlated to student performance. Computer games can thus be seen as a learning tool motivating players to acquire many competences. Connolly et al. (2012) share the same view, seeing the role of challenge as a predictive factor with respect to game engagement and achievement. Similarly, in Ke et al.'s study (2015), the game-play actions include optimal challenge expectation for the user. These results can also be seen in Badea (2015), who concludes that the majority of participants in her study acknowledge the highly motivating quality of games, which are complemented by the relaxed class atmosphere when games are used.

However, despite the benefits reaped from the implementation of games and simulations concerning affective outcomes, some researchers underline that motivation is 
not always related to GBL, emphasizing cases where students who use games in solitary or collaborative environments experience no significant difference in terms of learning motivation (Chen et al., 2015). There are indeed cases where serious games are no more motivating than conventional instructional methods (Wouters et al., 2013). In Cela-Ranilla et al.'s survey (2014), despite the suitability of the 3D simulation environment, students do not feel highly motivated or particularly engaged, mostly because they prefer analysis to actions in the particular learning process.

\section{Faculty role}

The benefits of a pedagogical shift from a teacher-focused and lecture-based classroom to a student-centred, active-learning environment through the adoption of simulation-based strategies to achieve engagement are relevant to both students and instructors (Auman, 2011). There is a progression in student emotion from uncertainty and nervousness to satisfaction and excitement within the gaming experience. Auman (2011), as an instructor, provides a positive description: she is drawn in by student enthusiasm, her interest in the material is reinvigorated, she feels empowered in her teaching, and ready to guide her class. In this context, it's easy to see how instructors ought to play a significant role in motivating and engaging students to achieve learning goals. De Porres and Livingston (2016) concur with Auman (2011), as their study also indicates increased levels of excitement in doctoral students studying Computer Science, when evaluated in a post-test intervention.

Faculty acting as motivators are key in engaging students in the learning process, working to ensure focus on pre-existing knowledge, as well as to transfer knowledge to game settings (Lameras et al., 2016), to reward students for their effort, and support them by providing continuous guidance and pathways for further consideration. The quality of the teacher/facilitator has a strong influence on the learning satisfaction of the students. Also, instructors should facilitate and engage students via in-game discussion forums to help overcome misconceptions, and to lead the game-based learning. The way instructors interact, facilitate and motivate students to construct GBL experiences depends on the design stage, particularly on the way games are incorporated into the curriculum in a traditional course (Wouters et al., 2013). This is because motivation exhibits a significant correlation with cognitive and skill performance (Woo, 2014). In research conducted by Franciosi (2016), despite faculty acknowledging the beneficial impact of games on student motivation, they nevertheless, remain doubtful about the effectiveness of games in learning outcomes, thus resulting in neutral attitudes. Interestingly, although instructors perceive simulations as engaging learning technologies, they do not however consider them superior to traditional teaching methods (Tanner et al., 2012).

Another aspect, less frequently discussed in the relevant literature, is students' performing self-assessments with regard to effective learning, as seen in Jones and Bursens study (2015). This ability is supported by constructivism, since simulations are developed in an active learning environment, where faculty act more as facilitators rather than as instructors and students are provided with feedback to carry out their self-assessments.

\section{Attitudes and satisfaction}

A vital element in achieving learning goals is the relationship between motivational processing and the outcome processing (satisfaction), especially in an online instructional 
game, as seen in the experiment carried out by Huang et al. (2010). There seems to be a significant relation between these two variables, which suggests that designers of DGBL need to consider extrinsic rewards to achieve motivational development and satisfaction. Learning satisfaction is strongly correlated with student motivation and attitude towards GBL before the game, with actual enjoyment and effort during the game, as well as with the quality of the teacher/facilitator (Mayer, 2013). Specifically, students with a higher level of inner motivation and positive attitude towards GBL are more likely to have higher learning expectations, and to experience more satisfaction in their GBL participation.

In general, most studies report that students develop a positive attitude toward the pedagogical adoption of games and simulations in education (Divjak \& Tomić, 2011; Bekebrede, 2011; Ibrahim et al., 2011; Beckem \& Watkins, 2012; Tanner et al., 2012; von Wangenheim et al., 2012; Halpern et al., 2012; Terzidou et al., 2012; Hanning et al., 2013; Giovanello, 2013; Cvetić et al., 2013; Kovalik \& Kuo, 2012; Li \& Tsai, 2013; Hainey et al., 2011; Boeker et al., 2013; Nkhoma et al., 2014; Costa et al., 2014; Chaves et al., 2015; Riemer \& Schrader, 2015; Angelini, 2016; Geithner \& Menzel, 2016). The participants in Dudzinski et al. (2013) respond positively towards a serious web-based game, describing the experience as interesting, stimulating and helpful, as well as a valuable addition to their pharmacy curriculum. Other students perceive simulation games as fun, but not particularly useful as an instructional method compared to lectures, and about equally useful as case discussions (Beuk, 2015). In another study, the majority of students show a positive attitude towards games, positing that they make subjects more fun and provide more opportunities for learning (Ibrahim et al., 2011). This finding is consistent with Bekebrede et al. (2011) on the perceptions of Dutch students belonging to the "net generation", who have been raised with technology-based games. Data reveals student preference towards active, collaborative and technology-rich learning via digital games that bring added value to the educational process.

For students, satisfaction is a deciding factor in their decision to continue using such learning methods (Liao \& Wang, 2011; Liao, 2015). Terzidou et al. (2012) discuss affective outcomes, especially the way interviewees feel before and after their participation in the game. Prior to participating, the interviewees report feelings of entertainment, fascination, and satisfaction before their participation in the game, which increase after use, indicating that participants find the use of 3D virtual game appealing.

Chen et al. (2010) reveal that the majority of students show negative feelings about online gaming. Shieh et al.'s (2010) mixed methodology research reveals that experimental groups show positive attitudes toward an innovative learning environment and outperform the control groups (in conventional classes). Some studies depict either neutral effects (Rajan et al., 2013; Beuk, 2015; Bolliger et al., 2015; Dankbaar et al., 2016; Strycker, 2016) or negative attitudes towards game use in the learning experience (Jiménez-Munguía \& Luna-Reyes, 2012). Students experience more anxiety and boredom during conventional courses, which acts as an impediment to acquiring substantial problem-solving skills. The educational benefits of GBL are particularly apparent in subjects over which students report greater anxiety, where it can be proven that increased enjoyment levels correlate positively with improvements in deep learning and 
higher-order thinking (Crocco et al., 2016). Liarokapis, (2010) show Computer Science students evaluating a serious online game, and finding it a valuable pedagogical tool, which is both useful and entertaining.

\section{Genre/familiarity issues}

Students achieving high scores respond more positively to online games compared to low achieving students. Regarding genre perceptions, male students express more enthusiasm towards digital gaming than female students, or at least spend more time playing computer games compared to girls (Hainey et al., 2011). This may be due to the fact that boys tend to be more familiar with computers and web-based technologies. Girls may choose to avoid digital game-based learning methods, due to their negative preconceptions about gaming, preventing them from harnessing the positive aspects of online gaming (Chen et al., 2010). These studies indicate a difference in perception based on gender when engaging in DGBL environments. However, research by Riemer and Schrader (2015) concluded that female students reported a more positive attitude and perception of affective quality compared to the male students. Also, high assessment scores in web-based games depend on the professional experience of the players. Unexpectedly, in Dzeng et al.'s experimental survey (2014), despite the high test scores achieved in both web-based and paper-based games, students without work experience achieve the highest post-test scores, probably because they are more familiar with using technological tools. The experiments in Erhel and Jamet's study (2013) indicate that serious games promote learning and motivation, provided they include features that prompt learners to actively process the educational content.

To sum up, games and simulations lead to improved affective outcomes for university students such as attitudes, motivation, emotional involvement, self-efficacy and satisfaction. A growing body of literature supports the positive attitude shown by students towards games and simulations, as they consider them essential instructional tools that provide motivation and engagement in an active learning environment.

\section{Discussion}

Research interest in the incorporation of games and simulations in higher education is constantly developing (Girard et al., 2013). The pedagogical shift, from lecture-centred to student-centred environments and the increasing use of games as innovative learning technologies, calls for a transformation in higher education. In this respect, games and simulations are expected to play a significant role in the learning process. In the present study, the focus is on the positive effects of games and simulations on university students' learning outcomes. The reviewed papers are diverse in terms of research objectives, theoretical background, methodological avenues adopted, game genres, scientific domain or delivery platform, and various perspectives concerning cognitive, behavioural and affective outcomes employed. Many articles $(n=123)$ are identified, providing either empirical results or offering meta-analytic evidence.

There seems to be a lack of shared definitions or taxonomy necessary for a common classification, which, therefore, results in terminological ambiguity (Klabbers, 2009). The majority of GBL researchers compare the effectiveness of implementing web-based learning games to conventional instructional options (Shin et al., 2015). 
Mapping the results, empirical evidence is identified with respect to cognitive learning outcomes including knowledge acquisition, conceptual application, content understanding and action-directed learning. Games and simulations are educational interventions, which create a supportive environment in which students may acquire knowledge across subjects and disciplines. Students have the opportunity to better understand theoretical concepts, provided that games are used as a supplement in traditional lecture-based courses. Additionally, simulations are often perceived as enjoyable learning tools, which require active and collaborative participation and contribute to the improvement of critical thinking and reasoning, higher-order- and metacognitive thinking. Simulations provide students the opportunity to observe the outcomes of their actions, and take responsibility for decision-making via problem-solving competencies, thus leading to a more active, transformative and experiential reception of knowledge.

Another important finding is that simulations have positive effects on both students and instructors. Positive outcomes exist when instructors set achievable learning goals, interact with students promoting knowledge, support, facilitate, and motivate them to construct new game-based knowledge (Kovalik \& Kuo, 2012; Lameras et al., 2016). Instructors are encouraged to design games and simulations in order to make students fully aware of game activities, providing all the while continuous instructional guidance. These results generally confirm the findings from prior systematic reviews and meta-analyses. However, findings diverge slightly in Young et al.'s survey (2012), who claim that there is limited or no evidence about the effective implementation of games in the lecture-based curriculum.

This review also covers behavioural outcomes, mainly the development of social, emotional, and collaborative skills, helping students to foster strong relationships with peers, empowering them to collaborate and work in groups more efficiently, become organised, adapt to new tasks, and resolve emerging conflicts. Furthermore, reality-based scenarios and action-oriented game activities promote fruitful interactions and meaningful feedback, which leads to collaborative construction of knowledge. Overall, digital games and simulations urge students to interact not only with the game, but with their instructors and co-players as well. These results have been extensively covered in the literature review, with the majority of researchers agreeing with the current study's results, confirming the positive effects of games and simulations on the behavioural level of learning outcomes (Bellotti et al., 2013; Tsekleves et al., 2014; Fu et al., 2016; Carenys \& Moya, 2016).

However, although most reviews acknowledge the positive effects of games in behavioural outcomes, some reviewed studies contradict these positive findings, claiming that teamwork is a controversial issue when it comes to the improvement of knowledge sharing. The use of games seems to decrease opportunities for peer interaction and communication with instructors (Bolliger et al., 2015), whereas playing individually is sometimes considered better than working in a team (Merchant et al., 2014). Also, in some cases, games and simulations through collaborative activities distract students and hinder learning (Dankbaar et al., 2016).

The current review makes a significant contribution by investigating the affective outcomes when incorporating games and simulations in the curriculum, especially motivational and engagement outcomes, emotional development, satisfaction, attitude, emotion, self-assessment, and self-efficacy. Results show that games and simulations 
motivate, engage and promote effective learning goals by providing opportunities for learners to actively experience, practice, interact, and reflect in a collaborative, game-based, and learner-centred setting. The measures evaluating student attitudes reveal an increasingly positive trend towards games and simulations, especially in post-interventions (Bekebrede et al., 2011; Giovanello et al., 2013; Costa et al., 2014; Angelini, 2016; Geithner \& Menzel, 2016).

To this end, there has been a purposeful highlighting of the instructor's role as facilitator and motivator in this literature review. Through in-game activities and extended discussion, instructors promote student interaction and help them overcome the lack of understanding of content curriculum and achieve better learning outcomes. The literature also stresses the role of emotional development, which facilitates improvement of learning outcomes. Specifically, there seems to be a progression in student emotion, from negative feelings including uncertainty, anxiety, nervousness, and disappointment during pre-intervention, to positive feelings of satisfaction, confidence, excitement, enjoyment, effort, fascination, and enthusiasm during in-game and post-game interventions (Huang et al., 2010; Hummel et al., 2011; Liao \& Wang, 2011; Terzidou et al., 2012; Woo, 2014; Liao et al., 2015).

Most of the pre-existing evidence is compatible with the findings of this systematic review (Sitzmann, 2011; Connolly et al., 2012; Wouters et al., 2013; Ritzhaupt et al., 2014; Gegenfurtner et al., 2014; Shin et al., 2015; Lameras et al., 2016; Carenys \& Moya, 2016; Fu et al., 2016; Warren et al., 2016). Nevertheless, one study indicates that the overall positive perception of students depends on the different forms of games (Riemer \& Schader, 2015), namely, simulations promote a less positive effect compared to quizzes and adventures. Some other studies diverge further in their findings, indicating either neutral (Rajan et al., 2013; Strycker, 2016; Franciosi, 2016) or negative student attitudes towards the use of games (Chen et al., 2010; Jiménez-Munguía \& Luna-Reyes, 2012). Also, there are limited results on the effect of games on student self-efficacy, with one study demonstrating moderate post-training self-efficacy (Sitzmann, 2011).

Comparing the findings of the current study with the findings of previous systematic reviews and meta-analyses leads to an interesting discussion. The results of the present review illustrate that the majority of the revised articles focus on different genres of games and simulations. The mostly represented genres are virtual/online games and simulations since they can enhance learning in certain disciplines, such as Computer Studies. This finding is in agreement with most of the previous reviews (e.g. Clark et al., 2015; Carenys \& Moya, 2016; Warren et al., 2016). Also, simulation games are found to be popular in this review, due to the fact that they are implemented in authentic learning environments, namely in Health Sciences and Biology. Also, in this study, a great representation of role - playing games and business simulation games are obviously resulted from the previous articles, due to the fact that they are implemented in specific academic disciplines, such as Business Management and Marketing. Nevertheless, in this review, serious games are not represented as much as in other reviews (e.g.Tsekleves et al., 2014; Fu et al., 2016).

Additionally, this study concentrates on the positive effects of games and simulations on learning outcomes, a finding that is compatible with previous reviews (e.g. Bellotti et al., 2013; Lameras et al., 2016; Clark et al., 2015. This review confirms that games and simulations contribute to cognitive learning outcomes, including knowledge acquisition, 
conceptual application, content understanding, and action-directed learning. Other previous reviewers echoed these findings (Smetana \& Bell, 2012; Shin et al., 2015; Wouters et al., 2013; Fu et al., 2016) emphasizing the important role of games in knowledge acquisition and content understanding. It has been illustrated that university students benefit from the incorporation of games into the learning process, if used as a supplement in traditional lectures, a finding that complies with other reviews (Sitzmann, 2011; Wouters et al., 2013). However, simulations' implementation is influenced by instructors' guidance and motivation, as these factors encourage faculty to design simulations to achieve learning outcomes.

This review also sheds light on behavioural outcomes of using games in instructional design. The emphasis is on the positive effects, namely the development of social and soft skills, emotional skills, the empowerment of collaboration with peers, and the promotion of interaction and feedback, findings that are in line with past reviews (Shin et al., 2015; Carenys \& Moya, 2016). Despite the positive behavioural effects of utilizing games, some reviews find collaboration and teamwork as a hindrance for learning. The application of games seems to decrease peer interaction and communication with faculty, whereas in Merchant et al.'s review (2014), playing individually is more preferable than playing collaboratively. The current review concludes by highlighting the affective outcomes, and the emphasis is given on motivational and engaging factors that lead to emotional development, satisfaction, self-efficacy and self-assessment, findings that are also documented in other reviews (Sitzmann, 2011; Hsu et al., 2012; Tsekleves et al., 2014).

To conclude, this review discusses the multitude of surveys on the cognitive, behavioural, and affective outcomes related to the use of playing games and simulations in higher education. The multi-dimensional analysis of the empirical data provides a framework for understanding the major outcomes of GBL. Despite the significant benefits in learning outcomes highlighted in this paper, the high cost of designing games and simulations is still a significant challenge. To overcome this cost barrier, governments, researchers, instructors, and game designers should collaborate to find affordable solutions, for enabling the development of games and simulations. Since this review does not concern itself with advanced aspects of learning, the focus should next turn to a metacognitive-oriented survey, which will study the promotion of metacognitive skills in students, such as self-regulation, self-reflection, self-awareness, evaluation, planning, building on the ideas of others, debating, and so forth.

\section{Future research}

Considering the above discussion points, and the importance of games and simulations as derived from the relevant literature, some suggested avenues for future research are as follows:

- Researchers should focus on applying the relevant theoretical frameworks, such as cognitivism, constructivism, and socio-cultural perspectives to cognitive, behavioural and affective outcomes, respectively.

- More research should be conducted investigating gender issues with respect to the effectiveness of games on developmental aspects of behaviour, such as scaffolding and immersion, to counteract the present gap in the existing literature. 
- Comparative surveys should be included with a design focused on different target groups (adult students, or K-12 students in laboratory conditions).

- Evaluation models via a mixed-method design are encouraged, especially to investigate how game designers could tailor game designs to applying different learning preferences and styles.

- University instructors should take a more active role in the alignment of games with the curriculum ensuring that games and simulations are implemented in a blended learning module (face-to-face, online material, etc.), or even acting as games masters, scaffolding virtual experiences to university learners.

- Faculty should design games with a view to multiplayer cooperation to achieve effectiveness in learning outcomes. Students should also be involved as co-designers, recommending innovative ideas and radical approaches in an effort to meet their own needs. An innovative approach is the adoption of metagames (Young et al., 2012), which consist of additional learning resources (blogs, wikis, etc.) encouraging collaboration between players.

This study makes a significant contribution to research, since no other literature review or meta-analysis has been conducted so far investigating educational and web-based games and simulations with such an extensive subject and discipline coverage in higher education. Today's demand for student-centred teaching methods to develop highly qualified learners, capable of learning in an active and collaborative environment, calls for the deployment of game-based activities and simulations that will enable them to face the challenges of the dawning era.

\title{
Acknowledgements
}

The research was sponsored by Laureate International Universities, through the "David Wilson Award for Excellence in Teaching and Learning", won by Dr. Dimitrios Vlachopoulos (2015-2017).

\section{Authors' contributions}

DV conceived the study. AM conducted the literature review and prepared the summaries and critical reflection on the corresponding literature. DV participated in the design of the study and analysis. AM participated in the preparation of the article's structure, graphs, and reference list. Both authors read and approved the final manuscript.

\section{Competing interest}

The authors declared that they have no competing interest.

\section{Publisher's Note}

Springer Nature remains neutral with regard to jurisdictional claims in published maps and institutional affiliations.

\author{
Author details \\ 'Laureate Online Education / European University Cyprus, Amsterdam, Netherlands. ${ }^{2}$ European University Cyprus,
} Nicosia, Cyprus.

Received: 28 November 2016 Accepted: 30 May 2017

Published online: 10 July 2017

References

Adams, D. M., Pilegard, C., \& Mayer, R. E. (2016). Evaluating the cognitive consequences of playing portal for a short duration. Journal of Educational Computing Research, 54(2), 173-195.

Ahmad, S. M. S., Fauzi, N. F. M., Hashim, A. A., \& Zainon, W. M. N. W. (2013). A study on the effectiveness of computer games in teaching and learning. International Journal of Advanced Studies in Computers, Science and Engineering, 2(1), 1.

Aldrich, C. (2009). Virtual worlds, simulations, and games for education: A unifying view. Innovate: Journal of Online Education, 5(5), 1.

Anderson, E. F., McLoughlin, L., Liarokapis, F., Peters, C., Petridis, P., \& Freitas, S. D. (2009). Serious games in cultural heritage. In M. Ashley \& F. Liarokapis (Eds.), VAST 2009: 10th International Symposium on Virtual Reality, Archaeology and Cultural Heritage 22-25 September 2009 (pp. 29-48). St. Julians, Malta: Eurographics Association. 
Andreu Andrés, M. A., \& García Casas, M. (2011). Perceptions of gaming as experiential learning by engineering students. International Journal of Engineering Education, 27(4), 795-804.

Angelini, M. L. (2016). Integration of the pedagogical models "simulation" and "flipped classroom" in teacher instruction. SAGE Open, 6(1). doi:10.1177/2158244016636430.

Angelini, M. L., García-Carbonell, A., \& Martínez-Alzamora, N. (2015). Estudio cuantitativo discreto sobre la simulación telemática en el aprendizaje del ingles. [Quantitative study about telematic simulation in learning]. RIE Revista Iberoamericana de Educación, 69(2), 51-68.

Arias Aranda, D., Haro Domiguez, C., \& Romerosa Martinez, M. M. (2010). An innovative approach to the learning process in management: The use of simulators in higher education. REVISTA DE EDUCACION, 353, 333-334.

Ariffin, M., Oxley, A., \& Sulaiman, S. (2014). Evaluating game-based learning effectiveness in higher education. Procedia Social and Behavioral Sciences, 123, 20-27 http://dx.doi.org/10.1016/j.sbspro.2014.01.1393. Accessed 11 Sept 2016.

Auman, C. (2011). Using simulation games to increase student and instructor engagement. College Teaching, 59(4), 154-161.

Backlund, P., \& Hendrix, M. (2013). Educational games-are they worth the effort? A literature survey of the effectiveness of serious games. In Games and virtual worlds for serious applications (VS-GAMES), 20135 th international conference on (pp. 1-8). IEEE.

Badea, M. (2015). English classes and effectiveness of games in higher education. Journal Plus Education, 13(2), 79-85.

Bausch, L., Beran, J., Cahanes, S., \& Krug, L. (2008). Physiological responses while playing Nintendo Wii sports. Journal of Undergraduate Kinesiology Research, 3, 19-25.

Beckem, J. M., \& Watkins, M. (2012). Bringing life to learning: Immersive experiential learning simulations for online and blended courses. Journal of Asynchronous Learning Networks, 16(5), 61-70.

Bekebrede, G., Warmelink, H. J. G., \& Mayer, I. S. (2011). Reviewing the need for gaming in education to accommodate the net generation. Computers \& Education, 57(2), 1521-1529.

Bellotti, F., Kapralos, B., Lee, K., Moreno-Ger, P., \& Berta, R. (2013). Assessment in and of serious games: An overview. Advances in Human-Computer Interaction, 2013, 1.

Beuk, F. (2015). Sales simulation games student and instructor perceptions. Journal of Marketing Education, 1-13 (2015). Doi: 0273475315604686.

Biddiss, E., \& Irwin, J. (2010). Active video games to promote physical activity in children and youth. Archives of Pediatrics and Adolescent Medicine, 164, 664-672.

Boeker M, Andel., P, Vach, W., \& Frankenschmidt, A. (2013). Game-based E-learning is more effective than a conventional instructional method: A randomized controlled trial with third-year medical students. PloS One $8(12)$ : e82328. doi:10.1371/journal.pone.0082328.

Bolliger, D. U., Mills, D., White, J., \& Kohyama, M. (2015). Japanese students' perceptions of digital game use for Englishlanguage learning in higher education. Journal of Educational Computing Research, 53(3), 384-408 0735633115600806.

Buckless, F. A., Krawczyk, K., \& Showalter, D. S. (2014). Using virtual worlds to simulate real-world audit procedures. Issues in Accounting Education, 29(3), 389-417.

Çankaya, S., \& Karamete, A. (2009). The effects of educational computer games on students' attitudes towards mathematics course and educational computer games. Procedia-Social and Behavioral Sciences, 1(1), 145-149.

Carenys, J., \& Moya, S. (2016). Digital game-based learning in accounting and business education. Accounting Education, 25(6), 598-651.

Cela-Ranilla, J. M., Esteve-Mon, F. M., Esteve-González, V., \& Gisbert-Cervera, M. (2014). Developing self-management and teamwork using digital games in 3D simulations. Australasian Journal of Educational Technology, 30(6), 634-651.

Chang, Y. C., Peng, H. Y., \& Chao, H. C. (2010). Examining the effects of learning motivation and of course design in an instructional simulation game. Interactive Learning Environments, 18(4), 319-339.

Chaves, R. O., von Wangenheim, C. G., Furtado, J. C. C., Oliveira, S. R. B., Santos, A., \& Favero, E. L. (2015). Experimental evaluation of a serious game for teaching software process modeling. IEEE Transactions on Education, 58(4), 289-296.

Chen, L., Chen, T.-L., \& Liu, H.-K. J. (2010). Perception of young adults on online games: Implications for higher education. TOJET: The Turkish Online Journal of Educational Technology, 9(3), 76-84.

Chen, C. H., Wang, K. C., \& Lin, Y. H. (2015). The Comparison of solitary and collaborative modes of game-based learning on Students' science learning and motivation. Educational Technology \& Society, 18(2), $237-248$.

Chiang, Y. T., Lin, S. S. J., Cheng, C. Y., \& Liu, E. Z. F. (2011). Exploring online game players' flow experiences and positive affect. The Turkish Online Journal of Educational Technology, 10(1), 106-114.

Clark, D. B., Tanner-Smith, E. E., \& Killingsworth, S. S. (2015). Digital games, design, and learning a systematic review and meta-analysis. Review of educational research, 86(1), 79-122 0034654315582065.

Connolly, T. M., Boyle, E. A., MacArthur, E., Hainey, T., \& Boyle, J. M. (2012). A systematic literature review of the empirical evidence on computer games and serious games. Computers \& Education, 59(2), 661-686.

Connolly, T., \& Stansfield, M. (2006). Using games-based eLearning technologies in overcoming difficulties in teaching information systems. Journal of Information Technology Education, 5(1), 459-476.

Connolly, T. M., Stansfield, M., \& Hainey, T. (2007). An application of games-based learning within software engineering. British Journal of Educational Technology, 38(3), 416-428.

Costa, G. J. M. D., Kikot, T., Fernandes, S., \& Águas, P. (2014). Why use-centered game-based learning in higher education? The case of cesim simbrand. Journal of Spatial and Organizational Dynamics, 2(3), 229-241.

Cózar-Gutiérrez, R., \& Sáez-López, J.M. (2016). Game-based learning and gamification in initial teacher training in the social sciences: An experiment with MinecraftEdu. International Journal of Educational Technology in Higher Education, 13(1), 1 (2016). doi: 10.1186/s41239-016-0003-4.

Crocco, F., Offenholley, K., \& Hernandez, C. (2016). A proof-of-concept study of game-based learning in higher education. Simulation \& Gaming, 47(4), 403-422 (2016). Doi: 1046878116632484.

Cvetić, B., Vasiljević, D., \& Danilović, M. (2013). DRP game: New tool to enhance teaching and learning in logistics and supply chain management. In 1st Logistics International Conference (pp. 299-303).

Dankbaar, M. E. W., Alsma, J., Jansen, E. E. H., van Merrienboer, J. J. G., van Saase, J. L. C. M., \& Schuit, S. C. E. (2016). An experimental study on the effects of a simulation game on students' clinical cognitive skills and motivation. Advances in Health Sciences Education, 21(3), 505-521.

DePorres, D., \& Livingston, R. E. (2016). Launching new doctoral students: Embracing the Hero's journey. Developments in Business Simulation and Experiential Learning, 43(1), 121-128. 
de Wit-Zuurendonk, L. D., \& Oei, S. G. (2011). Serious gaming in women's health care. BJOG: An International Journal of Obstetrics \& Gynaecology, 118(s3), 17-21.

Denholm, J., Protopsaltis, A., \& de Freitas, S. (2012). The value of team-based mixed-reality (TBMR) games in higher education. In European Conference on Games Based Learning (p. 571). Academic Conferences international limited.

de Smale, S., Overmans, T., Jeuring, J., \& van de Grint, L. (2015). The effect of simulations and games on learning objectives in tertiary education: A systematic review. In Games and Learning Alliance $4^{\text {th }}$ International Conference, GALA 2015 Rome.

Divjak, B., \& Tomić, D. (2011). The impact of game-based learning on the achievement of learning goals and motivation for learning mathematics-literature review. Journal of Information and Organizational Sciences, 35(1), 15-30.

Dudzinski, M., Greenhill, D., Kayyali, R., Nabhani, S., Philip, N., Caton, H., Ishtiaq, S., \& Gatsinzi, F. (2013). The design and evaluation of a multiplayer serious game for pharmacy students. In European Conference on Games Based Learning (p. 140). Academic Conferences international limited.

Dzeng, R. J., Lin, K. Y., \& Wang, P. R. (2014). Building a construction procurement negotiation training game model: Learning experiences and outcomes. British Journal of Educational Technology, 45(6), 1115-1135.

Elias, A. (2014). Simulating the European Union: Reflections on module design. International Studies Perspectives, 15(4), 407-422.

Erhel, S., \& Jamet, E. (2013). Digital game-based learning: Impact of instructions and feedback on motivation and learning effectiveness. Computers \& Education, 67, 156-167.

Farrington, J. (2011). From the research: Myths worth dispelling: Seriously, the game is up. Performance Improvement Quarterly, 24, 105-110

Felicia, P. (2011). Assessing how game-based learning is perceived in Irish education. In Proceedings of the 7th European Conference on Management Leadership and Governance: ECGBL 2011 (p. 168). Academic Conferences limited.

Flanagan, B., Nestel, D., \& Joseph, M. (2004). Making patient safety the focus: Crisis resource management in the undergraduate curriculum. Medical Education, 38(1), 56-66.

Franciosi, S. J. (2016). Acceptability of RPG simulators for foreign language training in Japanese higher education. Simulation \& Gaming, 47(1), 31-50 (2015). Doi: 1046878115608621.

Fu, K., Hainey, T., \& Baxter, G. (2016). A systematic literature review to identify empirical evidence on the use of computer games in business education and training. In 10th European Conference on Games Based Learning: ECGBL 2016 (p. 232).

García Carbonell, A., \& Watts Hooge, F. I. (2012). Investigación empírica del aprendizaje con simulación telemática. Revista Iberoamericana de Educación (versión digital)., 59(3), 1-11.

Gegenfurtner, A., Quesada-Pallarès, C., \& Knogler, M. (2014). Digital simulation-based training: A meta-analysis. British Journal of Educational Technology, 45(6), 1097-1114.

Geithner, S., \& Menzel, D. (2016). Effectiveness of learning through experience and reflection in a Project Management simulation. Simulation \& Gaming, 47(2), 228-256 (2016). Doi: 1046878115624312.

Giovanello, S. P., Kirk, J. A., \& Kromer, M. K. (2013). Student perceptions of a role-playing simulation in an introductory international relations course. Journal of Political Science Education, 9(2), 197-208.

Girard, C., Ecalle, J., \& Magnan, A. (2013). Serious games as new educational tools: How effective are they? A metaanalysis of recent studies. Journal of Computer Assisted Learning, 29(3), 207-219.

Gold, S. (2016). Design and effectiveness of a self-study pedagogical approach to using a simulation game in the classroom. Developments in Business Simulation and Experiential Learning, 43(1).

Gómez, M. (2014). Ciencias Sociales y gamificación, ¿una pareja con futuro? In J. Pagès (Ed.), Una mirada al pasado y un proyecto de futuro: investigación e innovación en didáctica de las ciencias sociales (pp. 257-262). Barcelona: Universitat Autónoma de Barcelona; Asociación Universitaria de Profesores de Didáctica de las Ciencias Sociales.

Gros, B. (2007). Digital games in education: The Design of Games Based Learning Environments. Journal of Research on Technology in Education, 40(1), 23-39.

Hainey, T., Connolly, T. M., Stansfield, M., \& Boyle, E. A. (2011). Evaluation of a game to teach requirements collection and analysis in software engineering at tertiary education level. Computers \& Education, 56(1), 21-35.

Halpern, D. F., Millis, K., Graesser, A. C., Butler, H., Forsyth, C., \& Cai, Z. (2012). Operation ARA: A computerized learning game that teaches critical thinking and scientific reasoning. Thinking Skills and Creativity, 7(2), 93-100.

Hämäläinen, R., \& Oksanen, K. (2014). Collaborative 3D learning games for future learning: Teachers' instructional practices to enhance shared knowledge construction among students. Technology, Pedagogy and Education, 23(1), 81-101.

Hannig, A., Kuth, N., Özman, M., Jonas, S., \& Spreckelsen, C. (2012). eMedOffice: A web-based collaborative serious game for teaching optimal design of a medical practice. BMC Medical Education, 12(1), 1.

Hannig, A., Lemos, M., Spreckelsen, C., Ohnesorge-Radtke, U., \& Rafai, N. (2013). Skills-o-mat: Computer supported interactive motion-and game-based training in mixing alginate in dental education. Journal of Educational Computing Research, 48(3), 315-343.

Helle, L., Nivala, M., Kronqvist, P., Gegenfurtner, A., Björk, P., \& Säljö, R. (2011). Traditional microscopy instruction versus processoriented virtual microscopy instruction: A naturalistic experiment with control group. Diagnostic Pathology, 6(1), 1.

Hess, T., \& Gunter, G. (2013). Serious game-based and nongame-based online courses: Learning experiences and outcomes. British Journal of Educational Technology, 44(3), 372-385.

Hou, H. T. (2015). Integrating cluster and sequential analysis to explore learners' flow and behavioral patterns in a simulation game with situated-learning context for science courses: A video-based process exploration. Computers in Human Behavior, 48, 424-435.

Hou, H. T., \& Li, M. C. (2014). Evaluating multiple aspects of a digital educational problem-solving-based adventure game. Computers in Human Behavior, 30, 29-38.

Hsu, Y.C., Ho, H. N. J., Tsai, C.C., Hwang, G.J., Chu, H.C., Wang, C.-Y., \& Chen, N-S. (2012). Research trends in technology-based learning from 2000 to 2009: A content analysis of publications in selected journals. Educational Technology \& Society, 15(2), 354-370.

Huang, W. H., Huang, W. Y., \& Tschopp, J. (2010). Sustaining iterative game playing processes in DGBL: The relationship between motivational processing and outcome processing. Computers \& Education, 55(2), 789-797.

Hummel, H. G., Van Houcke, J., Nadolski, R. J., Van der Hiele, T., Kurvers, H., \& Löhr, A. (2011). Scripted collaboration in serious gaming for complex learning: Effects of multiple perspectives when acquiring water management skills. British Journal of Educational Technology. doi:10.1111/j.1467-8535.2010.01122.x. 
Ibrahim, R., Wahab, S., Yusoff, R. C. M., Khalil, K., Desaru, I. N. S. T. E. D. T., \& Jaafar, A. (2011). Student perceptions of educational games in higher education: An empirical study. Issues in Information Systems, 12(1), 120-133.

Jiménez-Munguía, M. C., \& Luna-Reyes, L. F. (2012). Development of analytical abilities and collaborative learning assessment in undergraduate students through simulation games. In Electrical Communications and Computers (CONIELECOMP), 2012 22nd International Conference on (pp. 12-16). IEEE.

Jones, R., \& Bursens, P. (2015). The effects of active learning environments: How simulations trigger affective learning. European Political Science, 14(3), 254-265.

Kapralos, B., Hogan, M., Pribetic, A. I., \& Dubrowski, A. (2011). Virtual simulations and serious games in a laptop-based university: Gauging faculty and student perceptions. Interactive Technology and Smart Education, 8(2), 106-120.

Ke, F., Xie, K., \& Xie, Y. (2015). Game-based learning engagement: A theory-and data-driven exploration. British Journal of Educational Technology. doi:10.1111/bjet.12314.

Kikot, T., Costa, G., Magalhães, R., \& Fernandes, S. (2013). Simulation games as tools for integrative dynamic learning: The case of the management course at the University of Algarve. Procedia Technology, 9, 11-21.

Klabbers, J. H. G. (2009). Terminological ambiguity game and simulation. Simulation \& Gaming, 40(4), 446-463.

Kleinheksel, A. J. (2014). Transformative learning through virtual patient simulations: Predicting critical student reflections. Clinical Simulation in Nursing, 10(6), e301-e308.

Kovalik, C. L., \& Kuo, C. L. (2012). Innovation Diffusion: Learner benefits and instructor insights with the Diffusion Simulation Game. Simulation \& Gaming. 43(6), 803-824.

Lameras, P., Arnab, S., Dunwell, I., Stewart, C., Clarke, S., \& Petridis, P. (2016). Essential features of serious games design in higher education: Linking learning attributes to game mechanics. British Journal of Educational Technology. doi:10.1111/bjet.12467.

Lancaster, R. J. (2014). Serious game simulation as a teaching strategy in pharmacology. Clinical Simulation in Nursing, 10(3), e129-e137.

Li, Z. Z., Cheng, Y. B., \& Liu, C. C. (2013). A constructionism framework for designing game-like learning systems: Its effect on different learners. British Journal of Educational Technology, 44(2), 208-224.

Li, M. C., \& Tsai, C. C. (2013). Game-based learning in science education: A review of relevant research. Journal of Science Education and Technology, 22(6), 877-898.

Liarokapis, F., Anderson, E. F., Oikonomou, A. (2010). Serious games for use in a higher education environment. In Proceedings of the Emerging Games Platforms, Technologies and Applications Workshop (EGPTA'10), 15th Int I Computer Games Conference: Al, Interactive Multimedia, Virtual Worlds and Serious Games Louisville, Kentucky, USA (pp. 28-31).

Liao, Y. W., Huang, Y. M., \& Wang, Y. S. (2015). Factors affecting students' continued usage intention toward business simulation games an empirical study. Journal of Educational Computing Research, 53(2), 260-283.

Liao, Y.-W., \& Wang, Y.-S. (2011). Investigating the factors affecting students' continuance intention to use business simulation games in the context of digital learning. In International Conference on Innovation, Management and Service (pp. 119-124).

Lin, Y. L. (2016). Differences among different DGBLs learners. International Journal of Business and Management, $11(1), 181-188$

Lin, Y. L., \& Tu, Y. Z. (2012). The values of college students in business simulation game: A means-end chain approach. Computers \& Education, 58(4), 1160-1170.

Liu, C. C., Cheng, Y. B., \& Huang, C. W. (2011). The effect of simulation games on the learning of computational problem solving. Computers \& Education, 57(3), 1907-1918.

Ljungkvist, P., \& Mozelius, P. (2012). Educational games for self learning in introductory programming courses-a straightforward design approach with progression mechanisms. In Proceedings Of The 6th European Conference On Games Based Learning, ECGBL (pp. 285-293).

Lu, J., Hallinger, P., \& Showanasai, P. (2014). Simulation-based learning in management education: A longitudinal quasiexperimental evaluation of instructional effectiveness. Journal of Management Development, 33(3), 218-244.

Lukosch, H., Kurapati, S., Groen, D., \& Verbraeck, A. (2016). Microgames for situated learning a case study in interdependent planning. Simulation \& Gaming, 47(3), 346-367 (2016). Doi: 1046878116635468.

Mayer, I., Warmelink, H., \& Bekebrede, G. (2013). Learning in a game-based virtual environment: A comparative evaluation in higher education. European Journal of Engineering Education, 38(1), 85-106.

McLoughlin, C., \& Lee, M. J. W. (2008). The three P's of pedagogy for the networked society: Personalization, participation, and productivity. International Journal of Teaching and Learning in Higher Education, 20(1), 10-27.

Merchant, Z., Goetz, E. T., Cifuentes, L., Keeney-Kennicutt, W., \& Davis, T. J. (2014). Effectiveness of virtual reality-based instruction on students' learning outcomes in K-12 and higher education: A meta-analysis. Computers \& Education, 70, 29-40.

Mueller, F., Agamanolis, S., \& Picard, R. (2003). Exertion interfaces: Sports over a distance for social bonding and fun. In Proceedings of the SIGCHI conference on Human factors in computing systems (pp. 561-568). ACM.

Nadolny, L., \& Halabi, A. (2015). Student participation and achievement in a large lecture course with game-based learning. Simulation \& Gaming, 47(1), 51-72 (2015). Doi: 1046878115620388.

Navidad, F. C. (2013). Students' devised classroom games-simulations: An innovative tool on mathematics achievement and motivation in nursing students. International Proceedings of Economics Development and Research, 60, 14-18. doi:10.7763/PEDR.

Nkhoma, M., Calbeto, J., Sriratanaviriyakul, N., Muang, T., Ha Tran, Q., \& Kim Cao, T. (2014). Towards an understanding of real-time continuous feedback from simulation games. Interactive Technology and Smart Education, 11(1), 45-62.

Pasin, F., \& Giroux, H. (2011). The impact of a simulation game on operations management education. Computers \& Education, 57(1), 1240-1254.

Peterson, M. (2010). Computerized games and simulations in computer-assisted language learning: A meta-anlysis of research. Simulation \& Gaming, 41(1), 72-93.

Pløhn, T. (2013). Nuclear mayhem-a pervasive game designed to support learning. In European Conference on Games Based Learning (p. 475). Academic Conferences international limited.

Poikela, P., Ruokamo, H., \& Teräs, M. (2015). Comparison of meaningful learning characteristics in simulated nursing practice after traditional versus computer-based simulation method: A qualitative videography study. Nurse Education Today, 35(2), 373-382.

Rajan, P., Raju, P., \& Sankar, C.S. (2013). Serious Games to Improve Student Learning in Engineering Classes. Paper presented at $120^{\text {th }}$ ASEE Annual Conference \& Exposition, 23-26 June, 2013, Atlanta, Georgia. https://peer.asee.org/ 22448 Accessed 2 Oct 2016. 
Ranchhod, A., Gurău, C., Loukis, E., \& Trivedi, R. (2014). Evaluating the educational effectiveness of simulation games: A value generation model. Information Sciences, 264, 75-90.

Renken, M., Peffer, M., Otrel-Cass, K., Girault, l., \& Chiocarriello, A. (2016). Computer simulations on a multidimensional continuum: A definition and examples. In Simulations as Scaffolds in Science Education (pp. 5-14). London: Springer.

Riemer, V., \& Schrader, C. (2015). Learning with quizzes, simulations, and adventures: Students' attitudes, perceptions and intentions to learn with different types of serious games. Computers \& Education, 88, 160-168.

Ritzhaupt, A., Poling, N., Frey, C., \& Johnson, M. (2014). A synthesis on digital games in education: What the research literature says from 2000 to 2010. Journal of Interactive Learning Research, 25(2), 261-280.

Robertson, B., Schumacher, L., Gosman, G., Kanfer, R., Kelley, M., \& DeVita, M. (2009). Simulation-based crisis team training for multidisciplinary obstetric providers. Simululation in Healthcare, 4(2), 77-83. doi:10.1097/SIH. Ob013e3181917cd.

Rutten, N., van Joolingen, W. R., \& van der Veen, J. T. (2012). The learning effects of computer simulations in science education. Computers \& Education, 58(1), 136-153.

Salen, K., \& Zimmerman, E. (2004). Rules of play: Game design fundamentals. Cambridge, MA, USA: MIT Press.

Sarabia-Cobo, C. M., Alconero-Camarero, A. R., Lavín-Alconero, L., \& Ibánez-Rementería, I. (2016). Assessment of a learning intervention in palliative care based on clinical simulations for nursing students. Nurse Education Today, 45, 219-224.

Sauve, L., Renaud, L., Kaufman, D., \& Marquis, J. S. (2007). Distinguishing between games and simulation: A systematic review. Education Technology \& Society, 10(3), 247-256.

Sawyer, B. (2002). Serious games: Improving public policy through game-based learning and simulation. USA: Woodrow Wilson International Center for Scholars.

Seng, W. Y., \& Yatim, M. H. M. (2014). Computer game as learning and teaching tool for object oriented programming in higher education institution. Procedia-Social and Behavioral Sciences, 123, 215-224.

Shieh, R. S., Chang, W., \& Tang, J. (2010). The impact of implementing technology-enabled active learning (TEAL) in university physics in Taiwan. Asia-Pacific Education Researcher (De La Salle University Manila), 19(3).

Shin, S., Park, J. H., \& Kim, J. H. (2015). Effectiveness of patient simulation in nursing education: Meta-analysis. Nurse Education Today, 35(1), 176-182.

Siewiorek, A., Saarinen, E., Lainema, T., \& Lehtinen, E. (2012). Learning leadership skills in a simulated business environment. Computers \& Education, 58, 121-135.

Siewiorek, A., Gegenfurtner, A., Lainema, T., Saarinen, E., \& Lehtinen, E. (2013). The effects of computer-simulation game training on participants' opinions on leadership styles. British Journal of Educational Technology, 44(6), 1012-1035.

Silvia, C. (2012). The impact of simulations on higher-level learning. Journal of Public Affairs Education, 18(2), 397-422.

Sitzmann, T. (2011). A meta-analytic examination of the instructional effectiveness of computer-based simulation games. Personnel Psychology, 64(2), 489-528.

Smetana, L. K., \& Bell, R. L. (2012). Computer simulations to support science instruction and learning: A critical review of the literature. International Journal of Science Education, 34(9), 1337-1370.

Söderström, T., Häll, L., Nilsson, T., \& Ahlqvist, J. (2014). Computer simulation training in health care education fuelling reflection-in-action? Simulation \& Gaming, 45(6), 805-828.

Stanley, D., \& Latimer, K. (2011). 'the Ward': A simulation game for nursing students. Nurse Education in Practice, $11(1), 20-25$.

Strycker, J. (2016). Utilizing a simulation within an online school technology leadership course. Online Learning Journal, 20(1), 130-144.

Swanson, E. A., Nicholson, A. C., Boese, T. A., Cram, E., Stineman, A. M., \& Tew, K. (2011). Comparison of selected teaching strategies incorporating simulation and student outcomes. Clinical Simulation in Nursing, 7(3), e81-e90.

Tanner, J. R., Stewart, G., Totaro, M. W., \& Hargrave, M. (2012). Business simulation games: Effective teaching tools or window dressing? American Journal of Business Education (Online), 5(2), 115.

Tao, Y. H., Yeh, C. C. R., \& Hung, K. C. (2015). Validating the learning cycle models of business simulation games via student perceived gains in skills and knowledge. Educational Technology \& Society, 18(1), 77-90.

Terzidou, T., Tsiatsos, T., Dae, A., Samaras, O., \& Chasanidou, A. (2012). Utilizing virtual worlds for game based learning: Grafica, a 3D educational game in second life. In 2012 IEEE 12th International Conference on Advanced Learning Technologies (pp. 624-628). IEEE.

Tiwari, S. R., Nafees, L., \& Krishnan, O. (2014). Simulation as a pedagogical tool: Measurement of impact on perceived effective learning. The International Journal of Management Education, 12(3), 260-270.

Tsekleves, E., Cosmas, J., \& Aggoun, A. (2014). Benefits, barriers and guideline recommendations for the implementation of serious games in education for stakeholders and policymakers. British Journal of Educational Technology, 47(1), 164-183. doi:10.1111/bjet. 12223.

van Roessel, L., \& van Mastrigt-lde J. (2011). Collaboration and team composition in applied game creation processes. DiGRA '11, proceedings of the 2011 DiGRA international conference, think design play, 1-14.

von Wangenheim, C. G., Savi, R., \& Borgatto, A. F. (2012). DELIVER!-an educational game for teaching earned value management in computing courses. Information and Software Technology, 54(3), 286-298.

Vos, L., \& Brennan, R. (2010). Marketing simulation games: Student and lecturer perspectives. Marketing Intelligence \& Planning, 28(7), 882-897.

Wang, C., Huang, C. C., Lin, S. J., \& Chen, J. W. (2016). Using multimedia tools and high-fidelity simulations to improve medical students' resuscitation performance: An observational study. BMJ Open, 6(9), e012195.

Wang, L. C., \& Chen, M. P. (2010). The effects of game strategy and preference-matching on flow experience and programming performance in game-based learning. Innovations in Education and Teaching International, 47(1), 39-52.

Warren, J. N., Luctkar-Flude, M., Godfrey, C., \& Lukewich, J. (2016). A systematic review of the effectiveness of simulation-based education on satisfaction and learning outcomes in nurse practitioner programs. Nurse Education Today, 46, 99-108.

White, B., Kahriman, A., Luberice, L., \& Idleh, F. (2010). Evaluation of software for introducing protein structure. Biochemistry and Molecular Biology Education, 38(5), 284-289. 
Willoughby, T. (2008). A short-term longitudinal study of internet and computer game use by adolescent boys and girls: Prevalence, frequency of use, and psychosocial predictors. Developmental Psychology, 44(1), 195-204.

Woo, J. C. (2014). Digital game-based learning supports student motivation, cognitive success, and performance outcomes. Educational Technology \& Society, 17(3), 291-307.

Wouters, P., \& van Oostendorp, H. (2013). A meta-analytic review of the role of instructional support in game-based learning. Computers \& Education, 60(1), 412-425.

Wouters, P., Van Nimwegen, C., Van Oostendorp, H., \& Van Der Spek, E. D. (2013). A meta-analysis of the cognitive and motivational effects of serious games. Journal of Educational Psychology, 105(2), 249-265.

Yang, J. C., Chen, C. H., \& Jeng, M. C. (2010). Integrating video-capture virtual reality technology into a physically interactive learning environment for English learning. Computers \& Education, 55(3), 1346-1356.

Yang, J. C., Chien, K. H., \& Liu, T. C. (2012). A digital game-based learning system energy for energy education: An energy conservation pet. The Turkish Online Journal of Educational Technology, 11(2), 27-37.

Yang, Y. C., \& Chang, C. L. (2013). Empowering students through digital game authorship: Enhancing concentration, critical thinking, and academic achievement. Computers \& Education, 68, 334-344.

Yin, C., Song, Y., Tabata, Y., Ogata, H., \& Hwang, G. J. (2013). Developing and implementing a framework of participatory simulation for mobile learning using scaffolding. Educational Technology \& Society, 16(2), 137-150.

Young, M. F., Slota, S., Cutter, A. B., Jalette, G., Mullin, G., Lai, B., Simeoni, Z., Tran, M., \& Yukhymenko, M. (2012). Our princess is in another castle a review of trends in serious gaming for education. Review of Educational Research, $82(1), 61-89$.

Zacharia, Z. C., \& Olympiou, G. (2011). Physical versus virtual manipulative experimentation in physics learning. Learning and Instruction, 21(3), 317-331.

Zyda, M. (2005). From visual simulation to virtual reality to games. Computer, 38(9), 25-32.

Submit your manuscript to a SpringerOpen ${ }^{\circ}$ journal and benefit from:

- Convenient online submission

- Rigorous peer review

- Open access: articles freely available online

- High visibility within the field

- Retaining the copyright to your article

Submit your next manuscript at $\boldsymbol{s p r i n g e r o p e n . c o m ~}$ 